Review Article

\title{
Lifestyle Modulators of Neuroplasticity: How Physical Activity, Mental Engagement, and Diet Promote Cognitive Health during Aging
}

\author{
Cristy Phillips \\ Department of Physical Therapy, AState, Jonesboro, AR, USA \\ Correspondence should be addressed to Cristy Phillips; cphillips@astate.edu
}

Received 11 February 2017; Revised 1 May 2017; Accepted 28 May 2017; Published 12 June 2017

Academic Editor: Azucena B. Losa

Copyright $\odot 2017$ Cristy Phillips. This is an open access article distributed under the Creative Commons Attribution License, which permits unrestricted use, distribution, and reproduction in any medium, provided the original work is properly cited.

\begin{abstract}
The number of the elderly across the globe will approximate 2.1 billion by 2050. Juxtaposed against this burgeoning segment of the population is evidence that nonpathological aging is associated with an increased risk for cognitive decline in a variety of domains, changes that can cause mild disability even before the onset of dementia. Given that pharmacological treatments that mitigate dementia are still outstanding, alternative therapeutic options are being investigated increasingly. The results from translational studies have shown that modifiable lifestyle factors-including physical activity, cognitive engagement, and diet-are a key strategy for maintaining brain health during aging. Indeed, a multiplicity of studies has demonstrated relationships between lifestyle factors, brain structure and function, and cognitive function in aging adults. For example, physical activity and diet modulate common neuroplasticity substrates (neurotrophic signaling, neurogenesis, inflammation, stress response, and antioxidant defense) in the brain whereas cognitive engagement enhances brain and cognitive reserve. The aims of this review are to evaluate the relationship between modifiable lifestyle factors, neuroplasticity, and optimal brain health during aging; to identify putative mechanisms that contribute positive brain aging; and to highlight future directions for scientists and clinicians. Undoubtedly, the translation of cutting-edge knowledge derived from the field of cognitive neuroscience will advance our understanding and enhance clinical treatment interventions as we endeavor to promote brain health during aging.
\end{abstract}

\section{Introduction}

The number of elderly across the globe will approximate 2.1 billion by the year $2050[1,2]$. Accompanying this increase will be the personal, social, and economic burden of care for individuals with age-related disorders. These challenges are even more worrisome given that nonpathological aging is associated with decrements in key regions of the brain vital for cognitive function and, thereby, decline in several cognitive domains (including memory, attention, speed of processing, and executive function) $[3,4]$, changes that may result in mild disability even prior to the onset of dementia. Notwithstanding, pharmacological treatments that mitigate dementia are still outstanding, creating an imperative to diversify efforts to find efficacious alternatives. Modifiable lifestyle factors are among the candidate therapeutics particularly well-poised to mitigate age-related disorders [5-11]. Evidence strongly suggests that the maintenance of adequate levels of physical activity (PA), engagement in cognitive stimulation, and optimization of nutritional intake can increase neural plasticity and resilience of the brain [12-15].

The ability of neurons in the brain to change and reorganize continuously to meet the dynamic demands of the internal and external environment is termed neuronal plasticity. This process is dependent on membrane depolarization of the neuron, stimulus-induced synaptic activity, and subsequent changes in dendritic morphology, central hallmarks of learning and memory. Importantly, long-term PA moderates processes that are cornerstone for neuroplasticity [16]. Van Praag et al. demonstrated that mice that were given voluntary access to running wheels exhibited selective enhancement of long-term potentiation (LTP) in the dentate gyrus [17], a phenomenon linked with concomitant increases 
in brain-derived neurotrophic factor (BDNF) [18]. Eadie et al. demonstrated that long-term PA significantly increased dendritic length, dendritic complexity, and spine density in the dentate gyrus of mice [19]. Stranahan et al. demonstrated that long-term voluntary wheel running in rats induced changes in spine density along with changes in arborization and spine morphology [20]. Altogether, these findings suggest that PA induces neuroplastic changes in brain structure and function and, therefore, may be an effective component of therapeutic regimes that aim to improve cognition. Interestingly, other work suggests that mental engagement and dietary factors also effectuate changes in plasticity by altering neurotrophic signaling, neurogenesis, inflammation, stress response, and antioxidant defense mechanisms, which are outcomes similar to those implicated in the cognitive response to $\mathrm{PA}[16]$.

Knowledge of the dynamic relationship between brain plasticity and lifestyle factors creates an imperative to better understand and harness these links to promote healthy aging and forestall the onset of disease. Several national bodies have affirmed this notion, including the National Institutes of Health [21], the Centers for Disease Control, the Alzheimer's Association, and the American Association of Retired Persons (AARP). Accordingly, the purpose of this review is to (1) explicate key lifestyle factors (in particular PA, cognitive engagement, and diet) that can be harnessed to enhance neuroplasticity and optimal brain health; (2) explore the putative mechanisms by which these factors affect agerelated biology; and (3) highlight implications for clinicians and researchers.

\section{Physical Activity}

Numerous studies have reported a robust relationship between higher levels of PA and improved learning and memory $[22,23]$. Epidemiological studies show that regular PA reduces the risk of cognitive decline in aging adults $[15,24-26]$, with some evidence intimating that midlife PA may be especially beneficial. A population-based study of PA at midlife, followed up 26 years later with an assessment of late-life cognitive function, found that groups who participated in PA during midlife exhibited a faster speed of processing along with better memory and executive function. Additionally, those in the moderate PA group were significantly less likely to have dementia in late life [15]. A meta-analysis of 29 randomized controlled trials $(n=2049)$ showed that aerobic exercisers exhibited improvements in attention, processing speed, memory, and executive function [27]. Another meta-analysis of 15 prospective studies ( $n=33,816$ persons without dementia) reported that PA consistently resulted in a protective effect at all levels of activity [28]. Findings from a study of school children clearly demonstrates a positive correlation between PA and academic performance [29]. Indeed, higher cardiorespiratory fitness levels have been associated with better performance on a relational memory task and greater hippocampal volumes in children [30], findings that have been recapitulated in adolescents $[31,32]$. Together, these results suggest that the pervasive central benefits of PA on cognition span age groups.

Clinical studies demonstrate a positive relationship between PA and brain structure and function. A neuroanatomical study of persons aged 55 to 79 years demonstrated that age-related declines in cortical tissue density in the frontal, temporal, and parietal cortices were significantly reduced as a function of cardiovascular fitness [33], an interesting fact given that these areas underlie executive function and yet exhibit the greatest rate of age-related decline in humans [34]. Another study of elderly persons showed a direct correlation between increased levels of PA and improved cognition, with increased hippocampal volume seen after chronic exercise [35], supporting the idea that PA may prevent age-related anatomical and physiological deterioration in the brain $[36,37]$.

Bolstering the notion of PA's positive central effects are preclinical and clinical studies demonstrating neuroprotective and neuroplastic effects across a variety of neurodegenerative and neuropsychiatric diseases [36, 38-44]. A recent systematic analysis of 38 animal and human studies reported that PA attenuates Alzheimer-related neuropathology and positively affects hippocampal-mediated cognitive function, particularly when deployed early in the disease process [36]. Findings from another systematic review and meta-analysis demonstrate that PA is beneficial for people with Parkinson's disorder, specifically in areas of physical functioning, health-related quality of life, strength, balance, and gait speed [45]. Moreover, a recent review of clinical trials demonstrated that acute and chronic exercise generally increased levels of trophic factors in plasma and serum in persons with neurodegenerative conditions, including those with multiple sclerosis [46]. Also, PA has shown clear and consistent promise in promoting neuroplasticity in persons with mood disorders and, thereby, improving behavioral and neurobiological outcomes [38, 47], effects that extend to persons with posttraumatic stress disorder [48]. In persons with schizophrenia, evidence suggests that PA improves global cognition, working memory, social cognition, and attention [49]. A randomized controlled trial in persons with schizophrenia demonstrated that PA induced a $12 \%$ increase in hippocampal volume relative to nonexercisers [50]. While the dynamic cellular and molecular cascades that underlie the association between PA, cognition, and brain structure and function have yet to be elucidated fully, several modifiable mechanisms that alter neural plasticity have garnered increased attention recently, especially neurotrophic signaling, neurogenesis, inflammation, stress response, and antioxidant defense mechanisms [16]. Admittedly, an exhaustive review of all factors related to cognitive aging is beyond the scope of this article. Therefore, the reader is referred to the following excellent reviews for other factors that have been implicated in cognitive aging [51-59].

2.1. Neurotrophic Signaling. Neurotrophins are essential modulators of PA-induced neural plasticity. As one of the most widely distributed neurotrophins in the brain, BDNF plays a critical role in the maintenance, growth, and synaptic plasticity of neurons that underlie emotion and cognition 
$[18,60-62]$ and also modifies neuronal excitability $[62,63]$. BDNF is centrally and peripherally upregulated [64-67] following acute and long-term PA $[68,69]$, changes that endure for days [70] and are prominent in the hippocampus [22]. While higher levels of training intensity are requisite for maximal effects [66, 71], both resistance [72] and aerobic [71] exercise can effectuate the increases in BDNF levels once sufficient intensity of PA is achieved.

Extending these studies to humans, it has been shown that moderate levels of PA mitigate cognitive decline in aging persons through putative mechanisms that involve BDNF. Laurin and colleagues demonstrated that PA levels were inversely correlated with the risk for cognitive impairment and all-cause dementia [73]. Lautenschlager and colleagues reported that persons with subjective memory impairments who were randomized to 6 months of aerobic exercise exhibited lower clinical dementia rating scores, increased delayed recall, and better outcomes on the cognitive subscale scores of the Alzheimer's Disease Assessment Scale relative to controls during an 18-month follow-up period [74]. Coelho and colleagues investigated the effects of acute aerobic exercise on BDNF levels in older persons with $\mathrm{AD}$ and found a significant correlation between BDNF levels and levels of PA [75], suggesting that long-term PA may persistently elevate BDNF levels and modulate cognitive function in older adults. The latter notion is important given that BDNF gene expression levels naturally decrease in age-related disorders such as $\mathrm{AD}$ [76]. Decrements in BDNF are problematic because retrograde transport of BDNF from the hippocampus to forebrain cholinergic neurons protects against neuronal damage and degeneration [66]. Moreover, the maintenance of basal BDNF levels is requisite for hippocampal neurogenesis [77]. Interestingly, while both PA and cognitive training improve cognitive function, only PA increases plasma BDNF levels in rodents, suggesting that an adequate level of PA is essential for BDNF-mediated plasticity [78]. Furthering this notion is work demonstrating that the blockade of BDNF on TrkB receptors reduced the positive effects of PA on synaptic plasticity [79].

Altogether, these results suggest that PA effectuates central neuroplastic adaptations via the optimization of BDNF levels. The ability of PA to enhance BDNF release and function in the synapse, to promote dendritic spine integrity, and to activate other cellular pathways that contribute to plasticity [80-83] is a cornerstone for homeostatic processes that maintain, repair, and reorganize circuits damaged during aging and disease.

2.2. Neurogenesis. The addition of new neurons to existing circuits through adult neurogenesis represents a unique form of synaptic plasticity. The majority of the neurons in the brain are formed in the womb. However, the brain maintains the ability to generate new neurons throughout life in certain regions (e.g., dentate gyrus and olfactory bulb) $[84,85]$. Importantly, preclinical work suggests that PA increases adult neurogenesis, synaptic plasticity, and learning in the dentate gyrus of the hippocampus. Van Praag and colleagues demonstrated that voluntary wheel running simultaneously increased bromodeoxyuridine-positive cell numbers (precursor cell proliferation) and improved water maze performance (learning) [17]. Schmidt-Hieber and colleagues showed that newly born neurons in the hippocampus exhibit a lower excitability threshold and enhanced capabilities for synaptic plasticity [86], altering the rate by which new dentate granule cells are functionally integrated into hippocampal circuitry [87]. Eadie et al. demonstrated that long-term PA significantly increased total length and complexity of dendrites. Fascinatingly, they also demonstrated that long-term PA induced a more immature state of dentate granule cells [19], suggesting that PA reopens windows of plasticity. Stranahan et al. demonstrated that long-term voluntary wheel running in rats induced changes in spine density along with changes in arborization and spine morphology [20]. Others demonstrated that PA and cognitive stimulation exert differential effects on neurogenesis in rodents [88-91]. Whereas PA increases proliferation of neural precursor cells, cognitive stimulation promotes survival of the newly born cells. Thus, the absence of complex stimulation can block differentiation into mature neurons [92].

Translating the preclinical work to humans, clinical investigations using functional magnetic imaging have demonstrated that long-term aerobic exercise ( 3 months) increased blood volume in the dentate gyrus of the hippocampus and improved performance on the modified Rey Auditory Verbal Learning Test [93]. A randomized controlled study of healthy community-dwelling older adults demonstrated that those who participated in moderate aerobic exercise 3 times per week for 12 months showed a significant increase in size in the right and left hippocampus with concomitant improvements in spatial memory, a reversal that mitigated 1-2 years of age-related loss in hippocampal volume [94]. Encouragingly, increases in hippocampal size have been correlated with increases in spatial memory performance in both healthy adults [94] and persons with mild cognitive impairment [95]. The fact that PA upregulates neuronal proliferation and increases plasticity offers much hope for exploiting newly born neurons to maintain hippocampal volume in healthy and high-risk populations during aging $[36,96]$.

2.3. Inflammation. Long-term PA upregulates antiinflammatory processes, an important finding given that chronic inflammation is mechanistically linked to cognitive impairment, mood disorders, cardiovascular diseases, and neurodegenerative disorders [22, 97]. Several studies have demonstrated that persons who regularly participate in PA have fewer viral and bacterial infections and a reduced incidence of systemic low-grade inflammation [98-102]. For instance, Kohut and colleagues studied the effects of PA on immune function and found that elderly individuals who participated in aerobic exercise (45 minutes per day, 3 days/week for 10 months) exhibited a reduction in plasma interleukin 6 (IL-6), interleukin 8 (IL-8), C-reactive protein (CRP), and tumor necrosis factor (TNF) levels [101]. A randomized control trial in sedentary elderly adults demonstrated that those who participated in a supervised exercise program (3 days/week for 6 months) showed improvement 
in their inflammatory profile [103]. Other studies suggest that the beneficial effects of long-term exercise on cognition may stem in part from anti-inflammatory factors, specifically IL-6 [104-107], IL-8 [108-110], CRP [111-113], and TNF [114-116]. These findings are in line with several recent reviews that found that long-term moderate intensity PA can exert anti-inflammatory and neuroprotective effects [117-122]. Moreover, a recent review explicated mechanisms that contribute to neuroinflammation-induced impairments in neurogenesis in several conditions (aging, Alzheimer's, traumatic brain injury, and stroke), underscoring the importance of therapeutics such as PA that target the interplay between multiple neuroplasticity substrates, not isolated factors per se [123]. Together, these studies offer hope that PA can be used to mitigate age-related changes in immune senescence and preserve cognitive function with aging.

2.4. Stress Response. The hypothalamic-pituitary-adrenal axis (HPA) is a neuroendocrine circuit that coordinates emotional, cognitive, autonomic, and neuroendocrine responses to acute and chronic stress. Acute deactivation and activation of the HPA effectuates various changes in brain activation patterns: significant deactivation occurs in the hippocampus, hypothalamus, medio-orbitofrontal cortex, and anterior cingulate cortex following stress [124], whereas significant activation occurs in the amygdala $[125,126]$. These activation patterns likely reflect adaptations to help a person recognize and counteract similar stressors in the future [127]. Conversely, persistent activation of the HPA as a result of chronic stress can mediate long-term changes in the stress response including damage to keys areas of the brain (e.g., prefrontal cortex, paraventricular neurons, and hippocampus) [127]. It has been shown that persistently elevated levels of glucocorticoids are neurotoxic [128, 129]. Specifically, HPA dysregulation induces neuronal atrophy secondary to changes in neurochemistry, resilience, and plasticity in the hippocampus [130].

Activation of the HPA is induced by corticotropinreleasing hormone $(\mathrm{CRH})$ in the paraventricular nucleus in response to a stressor challenge, which induces adrenocorticotropic hormone (ACTH) from the pituitary and, in turn, effectuates the release of glucocorticoids (cortisol in humans and corticosterone in rodents) from the adrenal glands [131]. Glucocorticoids then modulate the stress response along with metabolic, immunologic, and genetic functioning [132-134]. Notably, the release of cortisol following an HPA stress response occurs within the context of ongoing basal cortisol release. That is, cortisol is naturally secreted over a 24-hour period daily in the absence of stressors according to a diurnal cycle [135]. Notwithstanding, cortisol levels naturally vary in response to endogenous and exogenous factors (e.g., sleep wake cycle, exposure to light and dark, hormones, food consumption, and psychosocial variables) [136]. Thus, HPA function reflects an individual's basal diurnal secretion along with their response to ongoing endogenous and exogenous stress.

Negative feedback mechanisms tightly regulate the HPA response via mechanisms that involve high-affinity binding to mineralocorticoid receptors and low affinity glucocorticoid receptors [137]. Glucocorticoids "turn off" their own secretion by downregulating the release of hormones (CRH and ACTH), a response that then decreases mineralocorticoid and glucocorticoid receptor signaling and, in turn, downregulates the activity of the HPA to prestress baselines. Appropriate modulation of the HPA response appears paramount to brain health given several lines of evidence implicating stress-related hyperactivity and dysregulation of the HPA with age-related, neuropsychiatric, and neurodegenerative disorders [128, 133, 138-142].

Unfortunately, some evidence suggests that HPA changes may occur during the aging process. It has been shown that cortisol levels increase with age $[143,144]$ and diurnal slopes flatten [144-147]. Aging also engenders decreased glucocorticoid sensitivity and impaired negative feedback, changes that could prolong the stress response [148]. Finally, the HPA axis may become dysregulated in aging persons following exposure to chronic stress (e.g., health impairments, loss of function, and bereavement) [149]. With time, these changes may effectuate systemic changes that are deleterious to physical and cognitive health. Indeed, increased basal cortisol levels are associated with hippocampal-related memory impairments [150] and frailty [151], whereas lower levels of basal cortisol are associated with longevity [152].

Fortunately, a bevy of research suggests that longterm, voluntary PA mitigates an overactive stress response $[153,154]$. Supporting this notion is evidence that exercise reduces the response to stressor challenge [155], an effect that may stem from exercise-induced fluctuations of glucocorticoid and mineralocorticoid receptor expression in the brain $[155,156]$. The ability of PA to attenuate rises in cortisol levels may be especially important for preventing hippocampal atrophy [157-159] and for reversing cognitive deficits in the aging population $[94,160]$ given that hippocampal neurons exposed to persistently elevated glucocorticoids retract their dendrites and exhibit fewer dendritic spines [161]. Also, preclinical evidence suggests that the degree of dendritic branching in hippocampal neurons and overall number of dendritic spines increase with voluntary wheel running $[19,20,162]$, potentially mitigating the effects of stress exposure. Together, this evidence suggests that PA may bolster physiological resilience by optimizing the stress response during aging.

2.5. Antioxidant Protection. Humans have a highly evolved antioxidant system designed to protect neurons from oxidative stress. By definition, oxidative stress is an imbalance between antioxidants and reactive oxygen species (ROS) (e.g., superoxide, hydrogen peroxide, and hydroxyl radical) [163]. Oxidative stress is widely deleterious in the central nervous system given that reactive oxygen species damage proteins, DNA, and lipids [164] and the fact that the brain has high metabolic demands and low antioxidant capacity [165, 166]. Notwithstanding, aerobic exercise decreases overall levels of ROS and increases adaptations to ROSinduced lipid peroxidation $[167,168]$. These mechanisms stem in part from the ability of PA to increase antioxidant gene expression (e.g., superoxide dismutases and glutathione peroxidase) and, thereby, antioxidant enzymatic activities in 
the brain $[167,169]$. Together, these studies suggest that long-term exercise optimizes redox homeostasis. Such is important for aging persons given that the kinase proteins that induce structural and functional changes in synapses require specific redox environments and that synaptic activity can be modulated via ROS levels.

\section{Cognitive Engagement as a Component of Healthy Lifestyle}

Convergent evidence suggests that engagement in mental activity also conveys neuroprotective and neuroplastic benefits during aging. Higher levels of education, a proxy for cognitive reserve, are associated with a reduced risk for cognitive impairment [170, 171], even in those with high-risk genetic backgrounds (e.g., apolipoprotein E4 carriers) [172, 173], possibly by increasing the threshold at which impairments become clinically manifest [174]. Another study demonstrates that higher education is protective against cognitive deficits in elderly individuals with white matter lesions [175]. Moreover, persons engaged in cognitively demanding occupational [176-179], leisure [180, 181], and social activities exhibit a reduced risk for cognitive decline with aging [13, 14, 176-180, 182-188]. Leisure activities that have demonstrated procognitive effects include reading, discussion groups, computer usage, participation in card and board games, solving puzzles, playing musical instruments, and learning a second language [180, 189-194]. Social activities that have demonstrated procognitive effects include traveling; attending theater, concerts, or art events; participating in social groups or pension organizations; socializing with family; and dancing [180, 191, 192, 194].

Underlying the effects of mental, leisure, and social engagement on cognition is a concept called "reserve." According to the reserve hypothesis, impairments in cognition become manifest after a pool of brain and cognitive resources is depleted. Brain reserve refers to structural differences that increase tolerance to pathology, whereas cognitive reserve refers to variability in approach to task performance. The idea of brain reserve derives from studies showing that the occurrence of dementia is lower in persons with larger brain weights $[195,196]$ and that persons who engage in intellectually stimulating activities experience less hippocampal atrophy with aging [197]. Cognitive reserve suggests that a person can mitigate the effects of brain pathology by deploying pre-existing processing approaches or by deriving alternative strategies [198, 199]. By corollary, persons with decreased brain or cognitive reserve are more likely to exhibit clinical impairments with age- or disease-related insult given their fewer brain resources, whereas those with a higher reserve have more resources to rely upon following age- or disease-related insult, raising their threshold for clinical impairments.

Contemporary views of brain and cognitive reserve espouse more nuanced conceptualizations. Enriched environments infused with challenging activities are thought to effectuate the formation of new dendritic branches and synapses. These morphological changes then deepen the brain's capacity to resist insult while increasing augmentation of glial support cells, enhancement of the brain's capillary network, and the induction and incorporation of new neurons [200]. Indeed, preclinical work shows that stimulating environments increase neurogenesis $[17,201,202]$ and upregulate BDNF [203-205], benefits that contribute to neural plasticity and extend to aging animals [206]. Enriched physical and social environments may provide short-lived mild to moderate stressors that induce locus coeruleus neurons to release noradrenaline and facilitate the formation and maintenance of adaptive memories [47], a process that could enhance adaptive structural changes in the brain (brain reserve) and cognitive and socioemotional learning (cognitive reserve). Supporting the latter notion is a multiplicity of studies showing that mental and socioemotional factors-including positive coping, optimism, sense of purpose, self-efficacy, and social support-are correlated with the stress response [207], are essential for the maintenance of high resilience [208-215], and are vital for mitigating age-related cognitive decline [216-218].

Another strategy that is garnering increased attention for enhancing brain and cognitive reserve is mindfulness meditation. A meta-analytic review (of 21 studies with approximately 300 participants) by Fox and colleagues examined the structural brain changes associated with mindfulness meditation and found that several brain regions consistently exhibited morphological differences in practitioners: the frontopolar cortex, sensory cortex, insula, anterior and mid-cingulate, hippocampus, and orbitofrontal cortex [219]. These areas are known to participate in awareness, attention, and emotional regulation, but are adversely affected in age-related disease and mood disorders $[220,221]$. Tang and colleagues [222] reviewed a myriad of studies to determine the effects of mindfulness meditation on structural brain changes, functional activation, and neural connectivity. These authors reported that mindfulness meditation was associated with structural (in the prefrontal cortex, anterior and posterior cingulate, insula, hippocampus, and amygdala), functional activation (prefrontal cortex, anterior cingulate, amygdala, insula, and orbitofrontal cortex), and neuroplastic changes (anterior cingulate cortex and prefrontal cortex) in the brain of meditators versus controls [222]. While the underlying mechanisms that contribute to the structural, functional, and neuroplastic changes associated with mindfulness have yet to be elucidated fully, it seems plausible that neurogenesis, dendritic branching, and synaptogenesis may be involved in emotional and cognitive regions of the brain, particularly given that meditation reduces cortisol release following stress [223-225].

Correspondingly, it is also held that cognitive rehabilitative protocols may serve as a form of enriched environment and effectuate cognitive gains in the aging population. Approaches to cognitive rehabilitation involve exercises carefully designed to harness neuroplasticity. Investigating the effects of cognitive rehabilitation in healthy older adults and persons with mild cognitive impairment, a Cochrane review demonstrated that immediate and delayed verbal recall improved significantly following training as compared to a no-treatment control condition [226]. Extending these 
studies further, another review assessed the effect of cognitive interventions on activities of daily living, mood, quality of life, and metacognition in persons with mild cognitive impairment. The authors found that computerized cognitive interventions conferred benefits to mood compared to controls, whereas therapist-based and multimodal interventions had a greater impact on activities of daily living and metacognitive outcomes than control conditions [227]. The notion that computerized cognitive rehabilitation may convey positive cognitive effects during aging is intriguing given that (1) these techniques can be deployed in a relatively quick and cost-effective manner; (2) the training can be personalized; (3) the rehabilitation can be used to target vulnerable and underserved populations, that is, persons who are homebound, residents of nursing homes, and those without access to transportation; and (4) preliminary evidence suggests residual effects are retained long-term (5 years) [228].

\section{Diet and Healthy Lifestyle}

Food consumption is an intrinsically motivated behavior with the potential to modulate brain structure and function. Driving this behavior is energy demand: whereas the brain comprises $2 \%$ of total body weight, it consumes $20 \%$ of the total energy derived from nutrients [229]. The exorbitant demand for energy derives from the requisite needs of neurons to maintain ionic gradients across their membranes to facilitate neurotransmission via oxidative metabolism. Accordingly, neurons are extremely sensitive to mitochondrial dysfunction and oxidative stress [166, 230, 231].

The centrality of feeding behavior for survivability makes it seem plausible that optimized food consumption represents a means to impact brain function positively. This putative effect stems in part from the ability of dietary factors to modulate synaptic plasticity by altering neurogenesis, inflammation, antioxidant defense mechanisms, neurotrophin levels, and energy metabolism [232], mechanisms similar to those induced by long-term PA [16]. For example, preclinical studies suggest that increased consumption of dietary fructose in the presence of an omega-3 fatty acid deficiency adversely affects learning and memory [233] by altering the function of molecules that are important in mitochondrial bioenergetics [234] in key brain regions such as the hippocampus [235]. Parallel evidence demonstrates that nutritional content, along with the level and frequency of food intake, effectuates changes in energy metabolism and neuroplasticity [229]. Population-based studies suggest that diets rich in polyphenols promote better performance in several cognitive abilities in a dose-dependent manner [9] and lower the risk of cognitive decline $[10,11]$ in older persons. Accordingly, it is increasingly held that bioactive substances in food represent a novel target for lifestyle interventions that may promote healthy brain aging and preserve cognitive function, especially in aging adults at risk for nutritional deficits [236]. Given that dietary modifications are considered by many to be safer and more easily integrated into lifestyle changes than conventional pharmacotherapeutics, several bioactive substances that have received intense investigation are reviewed below in brief.

Polyphenols (e.g., phenolic acids, stilbenes, lignans, flavonols, and anthocyanidins) comprise a class of approximately 8000 compounds with antioxidant properties. These compounds are found in fruits, vegetables, tea, wine, juices, plants, and some herbs. Whereas polyphenols are not considered "essential nutrients," convergent evidence does suggest that these factors can mitigate risk for neurodegenerative diseases, age-related cognitive decline, and oxidative stress [12, 237-245] via mechanisms involving the maintenance of metabolic homeostasis $[241,246]$ and the promotion of synaptic plasticity [241, 247]. Several dietary choices of polyphenols with putative neuroprotective [232], neuroplastic [248], neurogenic [249-251], and anti-inflammatory effects [252] have been explored, with a particular emphasis on curcumin, catechins, resveratrol, and omega- 3 fatty acids.

4.1. Curcumin. As a plant-based diarylheptanoid produced by the plant turmeric, curcumin is a component of yellow curry spice. This bright-yellow pigment was first isolated more than a century ago and has been used extensively in Indian medicine. Historically, it has been deployed to mitigation inflammation $[253,254]$, oxidative damage [255], and amyloid build-up [256, 257]. The antioxidant capabilities of curcumin appear to stem from its unique structure that can donate $\mathrm{H}$-atoms or transfer electrons from two phenolic sites, allowing it to scavenge free radicals easily. More recently, curcumin has garnered attention for its effects on neuroplasticity and its ability to ameliorate processes involved in brain aging and neurodegeneration.

Preclinical investigations show that dietary supplementation of curcumin 3 weeks prior to [258] and after [259] experimentally induced traumatic brain injury partially ameliorate the consequence of injury on markers of synaptic plasticity (e.g., BDNF and cAMP response element-binding protein), mechanisms that may partly involve the restoration of energy homeostasis [258-260] and facilitation of neurogenesis in the dentate gyrus of the hippocampus [261]. Also, curcumin may prevent secondary sequelae following brain injury by inhibiting the formation of oligomers and fibrils and the aggregation of amyloid proteins [262-264]. Interestingly, curcumin appears to cross the blood-brain barrier. Curcumin injected into the tail vein of rodents altered plaque formation in a model of $\mathrm{AD}$ [265]. A recent meta-analysis and systematic review of eight preclinical studies demonstrated that curcumin significantly improved neurological function in the central nervous system, an effect that was proportional to dosage [266].

Recently, preclinical studies have focused on the effects of curcumin administration on aging. One recent study has demonstrated that curcumin rescued age-related loss of hippocampal synapse input specificity of LTP by favoring $\mathrm{N}$-methyl-D-aspartic acid receptor activity [267]. Also, curcumin and its metabolite, tetrahydrocurcumin, increased the mean lifespan of at least three model organisms [268] and modulated the expression of aging genes in some models [269]. 
Extending these studies to humans, a large populationbased study of elderly nondemented Asians investigated the association between curry consumption and cognitive function, finding that persons who frequently consumed curry scored significantly better on the Mini-Mental State Examination relative to those who infrequently consumed curry [270]. Another 6-month randomized, placebo-controlled, double-blind, clinical study of curcumin in persons with progressive cognitive decline and memory found increased serum amyloid beta-40, but not improvements on the Mini-Mental State Examination [271]. Cox and colleagues investigated the acute, chronic, and acute-on-chronic effects of a curcumin formulation $(400 \mathrm{mg}$ ) on cognitive function, mood, and blood biomarkers in healthy older adults. They found that curcumin significantly improved (1) performance in attention and working memory 1 hour following administration as compared with placebo, (2) working memory and mood following 4 weeks of treatment, (3) alertness and contentedness 1 hour and 3 hours after a single dose following chronic treatment, and (4) LDL cholesterol via reduced total concentration [272]. Daily and colleagues examined the efficacy of curcumin for alleviating the symptoms of arthritis and found supportive treatment evidence for turmeric extract (about $1000 \mathrm{mg} /$ day of curcumin) [273], suggesting a translational avenue for its antiinflammatory effects. Derosa and colleagues evaluated the efficacy of curcuminoid supplementation on circulating concentrations of IL-6 in randomized controlled trials and reported a significant effect of curcumin in lowering circulating IL-6 concentrations, an effect that was more evident in patients with greater systemic inflammation [274]. A systematic review and meta-analysis of randomized controlled trials evaluated the efficacy of curcumin supplementation on circulating levels of TNF- $\alpha$ and reported a significant effect of curcumin in lowering circulating TNF- $\alpha$ concentration [275]. The ability of curcumin to mitigate chronic inflammatory processes is important because chronic inflammation dysregulates neurotransmission and trophic factor signaling and disrupts the processes of neurogenesis and neuroplasticity [276-279]. Moreover, chronic inflammatory processes can contribute to glutamatemediated excitotoxicity [279] and loss and dysfunction of glial cells [280-282].

To date, the results from preclinical research suggest that curcumin may benefit the brain and cognitive function during aging, but the level of evidence is still weak. One of the main limitations with curcumin studies and interventions is related to its limited bioavailability, a factor that could be addressed by chemical modification, conjugation with lipophilic compounds or coadministration with other compounds. No clinical trials to date provide conclusive evidence of the efficacy of long-term curcumin consumption for preventing or treating cognitive decline with aging. More studies are needed to explore the effects of this factor in persons with different genetic backgrounds and at different states of health and wellness.

4.2. Catechin Polyphenols. Found naturally in teas, catechin polyphenols are potent bioactive compounds with antioxidant $[283,284]$ and anti-inflammatory properties $[285,286]$. Their ability to donate hydrogens and scavenge reactive oxygen and nitrogen species underlies their antioxidant capabilities [283, 284]. Among the catechins found in tea, (-)epigallocatechin-3-gallate (EGCG) is a major constituent and therapeutic agent. EGCG has been shown to have neuroprotective functions that include antioxidant, iron chelating, and anti-inflammatory properties [287, 288]. Also, EGCG promotes amyloid precursor protein processing via the nontoxic amyloid precursor pathway [289] to reduce amyloid-beta pathology [290]. EGCG also appears to modulate cell survival genes [291].

Emerging preclinical and clinical evidence has suggested that EGCG modulates mechanisms involved in learning and cognitive decline. EGCG facilitated glutamate release by enhancing $\mathrm{Ca}^{2+}$ entry through voltage-dependent $\mathrm{Ca}^{2+}$ channels in isolated nerve terminals from rat cerebral cortex, a process linked to protein kinase C (PKC) activation $[289,291,292]$. This ability is important because increased release of glutamate in the brain has been shown to be a proxy for learning and memory [293, 294]. EGCG also affected synaptic plasticity as high-frequency stimulationevoked LTP was enhanced following preincubation of hippocampal slices with EGCG [295]. Another study has demonstrated that the application of EGCG modulated synaptic transmission and produced a dose-dependent improvement in the induction of LTP in the rat in vivo [296]. Moreover, long-term administration of green tea catechins to rats improved their reference and working memory-related learning ability and decreased reactive oxygen species concentrations in the hippocampus [297]. These results are not surprising given the relationship of EGCG to neurogenesis and BDNF: oral administration of EGCG enhances cell proliferation and increases the number of progenitor cells in the hippocampus of rodents $[250,251]$. Submicromolar concentrations of EGCG $(<0.1 \mu \mathrm{g} / \mathrm{ml})$ of unfractionated green tea and low concentrations $(<0.5 \mu \mathrm{M})$ of EGCG potentiated the neuritogenic ability of lowconcentration BDNF [298].

Parallel study has investigated the effects of catechins in humans. A large-scale study of middle-aged adults investigated the long-term association between polyphenol intake and cognitive performance, finding that catechins were positively associated with language and verbal memory [299]. A study of community-living Chinese adults aged 55 years or older demonstrated that consumption of black and oolong tea was associated with lower risks of cognitive impairment and decline after a 1- to 2-year follow-up [300]. A cross-sectional study of community-dwelling Japanese adults aged 70 years or older examined the association between green tea consumption and cognitive function, finding that higher consumption of green tea was associated with a lower prevalence of cognitive impairment as assessed by the Mini-Mental State Examination [301]. In a small interventional study in healthy volunteers, increased brain activity on functional magnetic resonance imaging in the dorsolateral prefrontal cortex, a proxy for memory processing, was reported in a dose-dependent manner following administration of green tea [302]. The effects of green tea 
consumption on the brain activity of healthy volunteers were measured using simplified EEG during passive activity in another study, with findings demonstrating significantly increased theta waves between 30 minutes and 1-hour postconsumption, suggesting a role for enhancing cognitive function [303].

4.3. Resveratrol. As a plant-based stilbene found in grapes, wine, and peanuts, resveratrol possesses significant free radical scavenging capabilities [304] given its three $\mathrm{OH}$ groups in positions 3, 4, and 5; aromatic rings; and a double bond in the molecule. Recently, it has garnered increased attention amidst reports of its neuroprotective and antiamyloid properties $[305,306]$ in rodents through mechanisms that likely involve oxidative stress [306], energy homeostasis [307], and neural plasticity [308, 309]. Bolstering this notion are cell culture studies that demonstrated that resveratrol reduced amyloid beta accumulation, ROS, and apoptosis [310] via modulation of nuclear factor-kB and Sirtuin 1 pathways [310-312]. Some preclinical studies suggest that resveratrol extends the lifespan $[310,313,314]$. For example, resveratrol increased cell survival by stimulating Sirtuin 2, a change that increased DNA stability, slowed aging, and extended the lifespan by $70 \%$ in yeast models [315]. Resveratrol added to the food of seasonal fish in early adulthood induced a dose-dependent increase of median and maximum lifespan [313]. Dietary consumption of resveratrol enhanced proliferative states in neuronal stem cells in the rat hippocampus [316]. Several parallel preclinical studies have demonstrated that resveratrol attenuated stress-induced learning deficits, depressive symptoms, and hippocampal degeneration by mechanisms that involved the restoration of BDNF [308, 309, 317-320]. Altogether, this preclinical data provides evidence that resveratrol treatment may be efficacious for improving mood and cognitive function.

Extending this line of investigation to humans, one small-scale, randomized, placebo-controlled, double-blind trial with Concord grape juice supplementation for 12 weeks demonstrated that older adults with memory decline but not dementia significantly improved in a measure of verbal learning [321]. Also, a double-blind, placebo-controlled study tested whether supplementation with resveratrol enhanced memory performance in older adults, finding that administration of $200 \mathrm{mg}$ of resveratrol daily with $320 \mathrm{mg}$ quercetin for six months duration in healthy older adults (50-80 years) effectuated greater hippocampal activity at rest (as assessed by functional magnetic resonance imaging) and improved memory performance [322]. Notwithstanding, low bioavailability of resveratrol is a major drawback [323]. Therefore, methods to enhance bioavailability (nanosized particles and oral lozenges) are being investigated [324-326].

4.4. Omega-3 Fatty Acids. Whereas transfats have deleterious effects in the brain, omega- 3 fatty acids (found in oily fish such as salmon, mackerel, herring, anchovies, menhaden, and sardines) have neuroprotective effects. Omega-3 fatty acids [e.g., $\alpha$-linolenic acid, eicosapentaenoic acid, and docosahexaenoic acid (DHA)] are polyunsaturated fatty acids that are vitally involved in neuronal physiology. Among the omega- 3 fatty acid family members is DHA, one of the most important because of its role in maintaining the structural balance of cell membranes, its ability to mediate phospholipid signal transduction at the synapse, and its ability to modulate enzymatic activity [327, 328]. Also, DHA stabilizes molecular mechanisms important for mitochondrial function [329], brain glucose utilization [330], and oxidative stress [331]. Dietary DHA also contributes to epigenetic changes that confer resilience to metabolic perturbations [332]. Notably, humans are reliant on consumption of dietary DHA from oily fish since the body is inefficient at synthesizing it. Clinical evidence suggests that dietary deficiencies can have adverse cognitive effects [333], yet one study demonstrated that less than half of women consume the recommended dietary allowance $[334,335]$, a trend that can be reversed with supplementation. Preclinical studies show that dietary restrictions in omega-3 fatty acids are associated with reductions in neuronal size and neurotrophin levels [336], whereas dietary supplementation reverses agerelated impairments in LTP and depolarization-induced glutamate transmitter release [337], effectuates increased levels of hippocampal neurotrophin levels [331], and upregulates genes that are important for maintaining synaptic function and plasticity [338].

A number of studies on omega-3 fatty acids have been extended to humans. Epidemiological studies demonstrate that high intake of fish rich in polyunsaturated fatty acids is associated with positive cognitive function. Results from the Rotterdam study demonstrate that high fish intake is inversely associated with incident dementia at baseline and at 2-year follow-up [339]. Elderly persons in the PAQUID cognitive and functional aging study who ate fish or seafood at least once a week exhibited a significantly lower risk of developing dementia in the 7-year follow-up period [340]. Similarly, community-dwelling elders in the Chicago Health and Aging Project who were in the upper quintile for consumption of saturated fat had a twofold increased risk for $\mathrm{AD}$ as compared to persons in the lowest quintile [341], suggesting that high intake of unsaturated, unhydrogenated fats may be protective against AD. Another study investigated whether omega-3 fatty acid intake is correlated with gray matter volume in brain structures associated with emotional circuitry, finding positive associations between reported dietary omega-3 intake and gray matter volume in the subgenual anterior cingulate cortex, right hippocampus, and right amygdala, intimating a mechanism by which omega-3 fatty acid intake may mediate memory, mood, and affect regulation [342]. Other study demonstrated that weekly consumption of baked or broiled fish is positively associated with increases in gray matter volumes in the hippocampus, precuneus, posterior cingulate, and orbitofrontal cortex [343]. Moreover, adults with subjective memory impairment who were administered fish oil (eicosapentaenoic acid + DHA) for 24 weeks in a randomized, doubleblind, placebo-controlled study exhibited increased cortical blood oxygen level-dependent activity in the right posterior cingulate and left superior frontal regions during a memory task as well as enhanced overall working memory performance [344], results that mirror earlier results of the 
Framingham Heart Study wherein DHA levels in the top quartile were associated with a $47 \%$ lower risk of all-cause dementia [345]. Another study investigated the effects of DHA and arachidonic acid (240 mg/day of DHA and arachidonic acid) on cognition in amnesic patients and found that DHA supplementation improved cognitive dysfunction secondary to aging and organic brain pathology [346]. Finally, a recent study demonstrated that higher-fasting plasma levels of omega-3 polyunsaturated fatty acids correlated with larger gray matter volume within the left rostral anterior cingulate cortex, a characteristic that partially mediated the relationship between cognitive flexibility in at-risk (apolipoprotein E4 carriers) older adults [347].

Admittedly, a National Institute of Health State of the Science Conference panel previously concluded that there is insufficient evidence to recommend omega-3 fatty acids for age-related cognitive decline. Notwithstanding, there are ongoing clinical trials designed to elucidate efficacy, trials that may be chiefly beneficial for persons in the lower quartile of omega-3 consumption or in at-risk groups for cognitive decline [348].

4.5. Caloric Restriction and Intermittent Fasting. In the context of adequate consumption of nutrients, caloric restriction conveys lifespan and healthspan benefits, including preservation of cognitive function. Convergent evidence suggests that a reduction of caloric intake by $20-40 \%$ extends the lifespan of organisms throughout phylogeny [349]. Population studies in Danish and Norwegian men and women revealed that involuntary caloric restriction without malnutrition for periods of 2-4 years reduced overall mortality rates [350]. Moreover, it has been shown that centenarians from Okinawa consumed $17 \%$ fewer calories than average Japanese adults, and they consumed 40\% fewer calories than American adults [333]. A recent review by Most and colleagues detailed the positive health benefits demonstrated from several recent randomized trials, reporting that caloric restriction in humans effectuate some of the same metabolic and molecular adaptations seen in preclinical models of longevity [351]. Finally, a $30 \%$ reduction in calories for 3 months has been associated with a $20 \%$ improvement in verbal memory in healthy elderly adults [352].

The mechanisms underlying caloric restriction appear to be multifold. Caloric restriction has been shown to increase cellular repair of DNA [353], reduce oxidative stress [354], improve the metabolism of glucose [355], and optimize immune [356] and neuroendocrine function [357, 358]. Moreover, caloric restriction counteracts age-related alterations in the expression of genes related to synaptic transmission [359]. For example, caloric restriction increases the expression of BDNF, TrkB, and NR2B subunits of NMDA receptors $[359,360]$ to mitigate age-related decrements in the hippocampus [361, 362]. Similarly, intermittent fasting exerts neuroprotective effects. It has been shown that synaptic resilience and function [363], levels of stress protein chaperones [364, 365], and neurotrophic factors [364] are increased following intermittent fasting, effects that may be particularly beneficial during times of injury [366].

\section{Conclusions and Future Directions}

Finding an effective treatment for age-related cognitive decline represents an unmet goal. However, considerable progress has been made in better understanding how PA and diet modulate common neuroplasticity substrates (neurotrophic signaling, neurogenesis, inflammation, stress response, and antioxidant defense mechanisms) in the brain [16]. Accordingly, this study highlights the importance of lifestyle modification for protecting cognitive function and brain health during aging and advocates for higher levels of PA and consumption of healthy foods to optimize neural plasticity. Once plasticity has been primed, cognitive training and rehabilitation can be used to facilitate the reorganization and proper function of cognitive circuits (to enhance brain reserve) and practice processing strategies and skills that translate to daily living (cognitive reserve). The deployment of techniques to optimize lifestyle are critical given the expanding size of the aging population juxtaposed with evidence that $97 \%$ of adults nationwide fail to exhibit healthy lifestyle characteristics [367]. Undoubtedly, the success of healthy lifestyle campaigns will require more emphasis on midlife, long-term, preventive approaches - with the goal of promoting positive health habits that delay progression and overt cognitive decline. Necessarily, these approaches should be paralleled by research that aims to disentangle the effects of lifestyle habits at different points along the aging and disease continuum.

Admittedly, large-scale, well-conducted, randomized controlled trials with PA, mental engagement, and dietary intake are only beginning to emerge. Undoubtedly, there is a need for future research in human populations that are well standardized and stratified in relation to genetic backgrounds, age, sex, and disease severity and duration. This research is needed to better understand the optimum mode, intensity, and duration of PA according to biologically distinct subgroups. Moreover, future studies will need to disentangle the individual and common pathways that exist between PA, mental activity, diet, social factors, and cognitive aging, particularly given evidence that various components may exert additive protection against cognitive decline [188]. In the area of cognitive rehabilitation, there remains a need to derive protocols whose outcomes reify as generalized, functional improvement in real-world environments [368]. While doing so, methodological standards will necessarily have to be considered more fully. It is known that noradrenergic function is essential for learning and memory [47] and that optimization of noradrenergic function (via PA or pharmacotherapeutics) during aging and disease [16, 47] may likely optimize learning and memory in certain populations (e.g., Down syndrome, Alzheimer's, and persons with mild cognitive impairment). Future studies should take into account the effects of noradrenergic function on cognitive training and rehabilitation outcomes in aging populations. Similarly, the duration of cognitive training and rehabilitation should be considered more fully. It is known that the effects of PA takes several weeks to reify at the behavioral level, a reflection of mechanisms that likely involve BDNF, neurogenesis, and the optimization of neurotransmitter 
levels [16]. Thus, it seems likely that the deployment of PA prior to cognitive training and rehabilitation could be used to normalize these factors to enhance outcomes, a notion that awaits further study. Finally, a greater understanding of antioxidant status in regard to plasma and brain bioavailability is needed, as are studies that disentangle dose-response effects, safety, tolerability, efficacy, and interactions with other dietary factors. The latter studies are imperative as it seems likely that the effects of nutrients in the brain are the product of a mélange of metabolites and interacting factors, not isolated factors per se. Together, these future efforts will help to ensure that research at the frontiers of cognitive neuroscience will provide a personalized approach to intervention during states of health, disease, and aging.

In the interim, the Alzheimer's Association and the AARP have launched public health initiatives that aim to foster a greater awareness of strategies that can be deployed to optimize cognitive function during aging. The initiative of the Alzheimer's Association is called Maintain Your Brain and promotes brain-centered healthy lifestyle choices (e.g., maintaining physical, mental, and social activity levels while concomitantly consuming a low-fat diet rich in antioxidants) [369]. Similarly, the AARP initiative, called Staying Sharp, encourages aging individuals to engage in a lifetime of learning and provides strategies to augment memory [370]. While neither program has been evaluated long-term, preliminary results from a two-year, multidomain, randomized, controlled study designed to prevent cognitive impairment are promising. The intervention consisted of PA, cognitive training, nutritional guidance, and social activities along with the management of vascular risk factors. The control group received regular health advice. After 2 years, a comprehensive neuropsychological test battery revealed a significant beneficial intervention effect on overall cognitive performance, including the domains of memory, executive function, and psychomotor speed. This novel study demonstrates the possibility of preventing cognitive decline using a multidomain intervention among older at-risk individuals [371]. It also highlights the importance in convincing patients of the value of a healthy lifestyle while concomitantly underscoring the importance of preventive public health policy.

\section{Abbreviations}

$\begin{array}{ll}\text { AARP: } & \text { American Association of Retired Persons } \\ \text { ACTH: } & \text { Adrenocorticotropic hormone } \\ \text { AD: } & \text { Alzheimer's disease } \\ \text { BDNF: } & \text { Brain-derived neurotrophic factor } \\ \text { CRH: } & \text { Corticotropin-releasing hormone } \\ \text { CRP: } & \text { C-reactive protein } \\ \text { DHA: } & \text { Docosahexaenoic acid } \\ \text { EGCG: } & \text { (-)epigallocatechin-3-gallate } \\ \text { HPA: } & \text { Hypothalamic-pituitary-adrenal axis } \\ \text { IL: } & \text { Interleukin } \\ \text { LTP: } & \text { Long-term potentiation } \\ \text { PA: } & \text { Physical activity } \\ \text { ROS: } & \text { Reactive oxygen species } \\ \text { TNF: } & \text { Tumor necrosis factor. }\end{array}$

\section{Conflicts of Interest}

No conflict of interest is declared.

\section{References}

[1] United Nations, Department of Economic and Social Affairs, Population Division, Ed., World Population Ageing 2015 (ST/ ESA/SER.A/390), United Nations, New York, NY, 2015.

[2] H. Shah, E. Albanese, C. Duggan et al., "Research priorities to reduce the global burden of dementia by 2025," Lancet Neurology, vol. 15, no. 12, pp. 1285-1294, 2016.

[3] T. L. Jernigan, S. L. Archibald, C. Fennema-Notestine et al., "Effects of age on tissues and regions of the cerebrum and cerebellum," Neurobiology of Aging, vol. 22, no. 4, pp. 581-594, 2001.

[4] K. Ball, D. B. Berch, K. F. Helmers et al., "Effects of cognitive training interventions with older adults: a randomized controlled trial," Journal of the American Medical Association, vol. 288, no. 18, pp. 2271-2281, 2002.

[5] A. J. Schuit, E. J. Feskens, L. J. Launer, and D. Kromhout, "Physical activity and cognitive decline, the role of the apolipoprotein e4 allele," Medicine and Science in Sports and Exercise, vol. 33, no. 5, pp. 772-777, 2001.

[6] R. D. Abbott, L. R. White, G. W. Ross, K. H. Masaki, J. D. Curb, and H. Petrovitch, "Walking and dementia in physically capable elderly men," Journal of the American Medical Association, vol. 292, no. 12, pp. 1447-1453, 2004.

[7] C. R. Richardson, A. M. Kriska, P. M. Lantz, and R. A. Hayward, "Physical activity and mortality across cardiovascular disease risk groups," Medicine and Science in Sports and Exercise, vol. 36, no. 11, pp. 1923-1929, 2004.

[8] R. S. Wilson, C. F. Mendes De Leon, L. L. Barnes et al., "Participation in cognitively stimulating activities and risk of incident Alzheimer disease," Jama, vol. 287, no. 6, pp. 742-748, 2002.

[9] E. Nurk, H. Refsum, C. A. Drevon et al., "Intake of flavonoidrich wine, tea, and chocolate by elderly men and women is associated with better cognitive test performance," The Journal of Nutrition, vol. 139, no. 1, pp. 120-127, 2009.

[10] E. E. Devore, J. H. Kang, M. M. Breteler, and F. Grodstein, "Dietary intakes of berries and flavonoids in relation to cognitive decline," Annals of Neurology, vol. 72, no. 1, pp. 135-143, 2012.

[11] M. Rabassa, A. Cherubini, R. Zamora-Ros et al., "Low levels of a urinary biomarker of dietary polyphenol are associated with substantial cognitive decline over a 3-year period in older adults: the Invecchiare in Chianti Study," Journal of the American Geriatrics Society, vol. 63, no. 5, pp. 938-946, 2015.

[12] F. Gomez-Pinilla, "Brain foods: the effects of nutrients on brain function," Nature Reviews. Neuroscience, vol. 9, no. 7, pp. 568-578, 2008.

[13] M. J. Hogan, R. T. Staff, B. P. Bunting, I. J. Deary, and L. J. Whalley, "Openness to experience and activity engagement facilitate the maintenance of verbal ability in older adults," Psychology and Aging, vol. 27, no. 4, pp. 849-854, 2012.

[14] D. M. Curlik 2nd and T. J. Shors, "Training your brain: do mental and physical (MAP) training enhance cognition through the process of neurogenesis in the hippocampus?" Neuropharmacology, vol. 64, pp. 506-514, 2013. 
[15] M. Chang, P. V. Jonsson, J. Snaedal et al., "The effect of midlife physical activity on cognitive function among older adults: AGES-Reykjavik Study," The Journals of Gerontology. Series A, Biological Sciences and Medical Sciences, vol. 65, no. 12, pp. 1369-1374, 2010.

[16] C. Phillips, "Physical activity modulates common neuroplasticity substrates in major depressive and bipolar disorder," Neural Plasticity, vol. 2017, Article ID 7014146, 37 pages, 2017.

[17] H. van Praag, B. R. Christie, T. J. Sejnowski, and F. H. Gage, "Running enhances neurogenesis, learning, and long-term potentiation in mice," Proceedings of the National Academy of Sciences of the United States of America, vol. 96, no. 23, pp. 13427-13431, 1999.

[18] K. K. Cowansage, J. E. LeDoux, and M. H. Monfils, "Brainderived neurotrophic factor: a dynamic gatekeeper of neural plasticity," Current Molecular Pharmacology, vol. 3, no. 1, pp. 12-29, 2010.

[19] B. D. Eadie, V. A. Redila, and B. R. Christie, "Voluntary exercise alters the cytoarchitecture of the adult dentate gyrus by increasing cellular proliferation, dendritic complexity, and spine density," The Journal of Comparative Neurology, vol. 486, no. 1, pp. 39-47, 2005.

[20] A. M. Stranahan, D. Khalil, and E. Gould, "Running induces widespread structural alterations in the hippocampus and entorhinal cortex," Hippocampus, vol. 17, no. 11, pp. 10171022, 2007.

[21] M. L. Daviglus, C. C. Bell, W. Berrettini et al., "NIH state-ofthe-science conference statement: preventing Alzheimer's disease and cognitive decline," NIH Consensus and State-ofthe-Science Statements, vol. 27, no. 4, pp. 1-30, 2010.

[22] C. W. Cotman, N. C. Berchtold, and L. A. Christie, "Exercise builds brain health: key roles of growth factor cascades and inflammation," Trends in Neurosciences, vol. 30, no. 9, pp. 464-472, 2007.

[23] C. W. Cotman and N. C. Berchtold, "Exercise: a behavioral intervention to enhance brain health and plasticity," Trends in Neurosciences, vol. 25, no. 6, pp. 295-301, 2002.

[24] M. Dik, D. J. Deeg, M. Visser, and C. Jonker, "Early life physical activity and cognition at old age," Journal of Clinical and Experimental Neuropsychology, vol. 25, no. 5, pp. 643653, 2003.

[25] E. B. Larson, L. Wang, J. D. Bowen et al., "Exercise is associated with reduced risk for incident dementia among persons 65 years of age and older," Annals of Internal Medicine, vol. 144, no. 2, pp. 73-81, 2006.

[26] L. J. Podewils, E. Guallar, L. H. Kuller et al., "Physical activity, APOE genotype, and dementia risk: findings from the cardiovascular health cognition study," American Journal of Epidemiology, vol. 161, no. 7, pp. 639-651, 2005.

[27] P. J. Smith, J. A. Blumenthal, B. M. Hoffman et al., “Aerobic exercise and neurocognitive performance: a meta-analytic review of randomized controlled trials," Psychosomatic Medicine, vol. 72, no. 3, pp. 239-252, 2010.

[28] F. Sofi, D. Valecchi, D. Bacci et al., "Physical activity and risk of cognitive decline: a meta-analysis of prospective studies," Journal of Internal Medicine, vol. 269, no. 1, pp. 107-117, 2011.

[29] R. W. Bass, D. D. Brown, K. R. Laurson, and M. M. Coleman, "Physical fitness and academic performance in middle school students," Acta Paediatrica, vol. 102, no. 8, pp. 832837, 2013.
[30] L. Chaddock, K. I. Erickson, R. S. Prakash et al., "A neuroimaging investigation of the association between aerobic fitness, hippocampal volume, and memory performance in preadolescent children," Brain Research, vol. 1358, pp. 172-183, 2010.

[31] M. M. Herting and B. J. Nagel, "Aerobic fitness relates to learning on a virtual Morris water task and hippocampal volume in adolescents," Behavioural Brain Research, vol. 233, no. 2, pp. 517-525, 2012.

[32] M. M. Herting and B. J. Nagel, "Differences in brain activity during a verbal associative memory encoding task in highand low-fit adolescents," Journal of Cognitive Neuroscience, vol. 25, no. 4, pp. 595-612, 2013.

[33] S. J. Colcombe, K. I. Erickson, N. Raz et al., "Aerobic fitness reduces brain tissue loss in aging humans," The Journals of Gerontology. Series A, Biological Sciences and Medical Sciences, vol. 58, no. 2, pp. 176-180, 2003.

[34] N. Raz, "Aging in the brain and its impact on cognitive performance: integration of structural and functional findings," in The Handbook of Aging and Cognition, F. Craik and T. A. Salthouse, Eds., pp. 1-90, Lawrence Erlbaum Associates, Mahwah, NJ, 2000.

[35] K. I. Erickson, R. S. Prakash, M. W. Voss et al., "Aerobic fitness is associated with hippocampal volume in elderly humans," Hippocampus, vol. 19, no. 10, pp. 1030-1039, 2009.

[36] C. Phillips, M. A. Baktir, D. Das, B. Lin, and A. Salehi, "The link between physical activity and cognitive dysfunction in Alzheimer disease," Physical Therapy, vol. 95, no. 7, pp. 1046-1060, 2015.

[37] M. W. Voss, C. Vivar, A. F. Kramer, and H. van Praag, "Bridging animal and human models of exercise-induced brain plasticity," Trends in Cognitive Sciences, vol. 17, no. 10, pp. 525-544, 2013.

[38] C. Phillips and A. Salehi, "A special regenerative rehabilitation and genomics letter: is there a "hope" molecule?" Physical Therapy, vol. 96, no. 4, pp. 581-583, 2016.

[39] C. Phillips, M. A. Baktir, M. Srivatsan, and A. Salehi, "Neuroprotective effects of physical activity on the brain: a closer look at trophic factor signaling," Frontiers in Cellular Neuroscience, vol. 8, p. 170, 2014.

[40] A. D. Smith and M. J. Zigmond, "Can the brain be protected through exercise? Lessons from an animal model of parkinsonism," Experimental Neurology, vol. 184, no. 1, pp. 31-39, 2003.

[41] W. Stummer, K. Weber, B. Tranmer, A. Baethmann, and O. Kempski, "Reduced mortality and brain damage after locomotor activity in gerbil forebrain ischemia," Stroke, vol. 25, no. 9, pp. 1862-1869, 1994.

[42] Y. Rolland, F. Pillard, A. Klapouszczak et al., "Exercise program for nursing home residents with Alzheimer's disease: a 1-year randomized, controlled trial," Journal of the American Geriatrics Society, vol. 55, no. 2, pp. 158-165, 2007.

[43] H. Chen, S. M. Zhang, M. A. Schwarzschild, M. A. Hernan, and A. Ascherio, "Physical activity and the risk of Parkinson disease," Neurology, vol. 64, no. 4, pp. 664-669, 2005.

[44] M. Hamer and Y. Chida, "Physical activity and risk of neurodegenerative disease: a systematic review of prospective evidence," Psychological Medicine, vol. 39, no. 1, pp. 3-11, 2009.

[45] V. A. Goodwin, S. H. Richards, R. S. Taylor, A. H. Taylor, and J. L. Campbell, "The effectiveness of exercise interventions for people with Parkinson's disease: a systematic 
review and meta-analysis," Movement Disorders, vol. 23, no. 5, pp. 631-640, 2008.

[46] C. Campos, N. B. Rocha, E. Lattari, F. Paes, A. E. Nardi, and S. Machado, "Exercise-induced neuroprotective effects on neurodegenerative diseases: the key role of trophic factors," Expert Review of Neurotherapeutics, vol. 16, no. 6, pp. 723-734, 2016.

[47] C. Phillips, A. Fahimi, D. Das, F. S. Mojabi, R. Ponnusamy, and A. Salehi, "Noradrenergic system in down syndrome and Alzheimer's disease a target for therapy," Current Alzheimer Research, vol. 13, no. 1, pp. 68-83, 2016.

[48] S. Rosenbaum, D. Vancampfort, Z. Steel, J. Newby, P. B. Ward, and B. Stubbs, "Physical activity in the treatment of post-traumatic stress disorder: a systematic review and meta-analysis," Psychiatry Research, vol. 230, no. 2, pp. 130-136, 2015.

[49] J. Firth, B. Stubbs, S. Rosenbaum et al., "Aerobic exercise improves cognitive functioning in people with schizophrenia: a systematic review and meta-analysis," Schizophrenia Bulletin, vol. 43, 2016.

[50] F. G. Pajonk, T. Wobrock, O. Gruber et al., "Hippocampal plasticity in response to exercise in schizophrenia," Archives of General Psychiatry, vol. 67, no. 2, pp. 133-143, 2010.

[51] M. K. Scullin and D. L. Bliwise, "Sleep, cognition, and normal aging: integrating a half century of multidisciplinary research," Perspectives on Psychological Science, vol. 10, no. 1, pp. 97-137, 2015.

[52] N. Ishikawa, K. Nakamura, N. Izumiyama-Shimomura et al., "Changes of telomere status with aging: an update," Geriatrics \& Gerontology International, vol. 16, Supplement 1, pp. 30-42, 2016.

[53] E. Epel, J. Daubenmier, J. T. Moskowitz, S. Folkman, and E. Blackburn, "Can meditation slow rate of cellular aging? Cognitive stress, mindfulness, and telomeres," Annals of the new York Academy of Sciences, vol. 1172, pp. 34-53, 2009.

[54] N. C. Ebner, H. Kamin, V. Diaz, R. A. Cohen, and K. MacDonald, "Hormones as "difference makers" in cognitive and socioemotional aging processes," Frontiers in Psychology, vol. 5, p. 1595, 2014.

[55] M. C. Morris, "Nutritional determinants of cognitive aging and dementia," The Proceedings of the Nutrition Society, vol. 71, no. 1, pp. 1-13, 2012.

[56] B. Caracciolo, W. Xu, S. Collins, and L. Fratiglioni, "Cognitive decline, dietary factors and gut-brain interactions," Mechanisms of Ageing and Development, vol. 136-137, pp. 5969, 2014

[57] X. Xu, "DNA methylation and cognitive aging," Oncotarget, vol. 6, no. 16, pp. 13922-13932, 2015.

[58] C. N. Harada, M. C. Natelson Love, and K. L. Triebel, "Normal cognitive aging," Clinics in Geriatric Medicine, vol. 29, no. 4, pp. 737-752, 2013.

[59] A. K. Dahl and L. B. Hassing, "Obesity and cognitive aging," Epidemiologic Reviews, vol. 35, pp. 22-32, 2013.

[60] B. S. Fernandes, M. Berk, C. W. Turck, J. Steiner, and C. A. Goncalves, "Decreased peripheral brain-derived neurotrophic factor levels are a biomarker of disease activity in major psychiatric disorders: a comparative meta-analysis," Molecular Psychiatry, vol. 19, no. 7, pp. 750-751, 2014.

[61] A. E. Autry and L. M. Monteggia, "Brain-derived neurotrophic factor and neuropsychiatric disorders," Pharmacological Reviews, vol. 64, no. 2, pp. 238-258, 2012.
[62] B. Lu and A. Figurov, "Role of neurotrophins in synapse development and plasticity," Reviews in the Neurosciences, vol. 8, no. 1, pp. 1-12, 1997.

[63] A. Figurov, L. D. Pozzo-Miller, P. Olafsson, T. Wang, and B. Lu, "Regulation of synaptic responses to high-frequency stimulation and LTP by neurotrophins in the hippocampus," Nature, vol. 381, no. 6584, pp. 706-709, 1996.

[64] P. Rasmussen, P. Brassard, H. Adser et al., "Evidence for a release of brain-derived neurotrophic factor from the brain during exercise," Experimental Physiology, vol. 94, no. 10, pp. 1062-1069, 2009.

[65] S. W. Tang, E. Chu, T. Hui, D. Helmeste, and C. Law, "Influence of exercise on serum brain-derived neurotrophic factor concentrations in healthy human subjects," Neuroscience Letters, vol. 431, no. 1, pp. 62-65, 2008.

[66] S. A. Neeper, F. Gomez-Pinilla, J. Choi, and C. Cotman, "Exercise and brain neurotrophins," Nature, vol. 373, no. 6510, p. 109, 1995.

[67] T. Seifert, P. Brassard, M. Wissenberg et al., "Endurance training enhances BDNF release from the human brain," American Journal of Physiology. Regulatory, Integrative and Comparative Physiology, vol. 298, no. 2, pp. R372R377, 2010

[68] M. W. Marlatt, M. C. Potter, P. J. Lucassen, and H. van Praag, "Running throughout middle-age improves memory function, hippocampal neurogenesis, and BDNF levels in female C57BL/6J mice," Developmental Neurobiology, vol. 72, no. 6, pp. 943-952, 2012.

[69] J. L. Abel and E. F. Rissman, "Running-induced epigenetic and gene expression changes in the adolescent brain," International Journal of Developmental Neuroscience, vol. 31, no. 6, pp. 382-390, 2013.

[70] N. C. Berchtold, N. Castello, and C. W. Cotman, "Exercise and time-dependent benefits to learning and memory," Neuroscience, vol. 167, no. 3, pp. 588-597, 2010.

[71] L. T. Ferris, J. S. Williams, and C. L. Shen, "The effect of acute exercise on serum brain-derived neurotrophic factor levels and cognitive function," Medicine and Science in Sports and Exercise, vol. 39, no. 4, pp. 728-734, 2007.

[72] J. F. Yarrow, L. J. White, S. C. McCoy, and S. E. Borst, "Training augments resistance exercise induced elevation of circulating brain derived neurotrophic factor (BDNF)," Neuroscience Letters, vol. 479, no. 2, pp. 161-165, 2010.

[73] D. Laurin, R. Verreault, J. Lindsay, K. MacPherson, and K. Rockwood, "Physical activity and risk of cognitive impairment and dementia in elderly persons," Archives of Neurology, vol. 58, no. 3, pp. 498-504, 2001.

[74] N. T. Lautenschlager, K. L. Cox, L. Flicker et al., "Effect of physical activity on cognitive function in older adults at risk for Alzheimer disease: a randomized trial," Jama, vol. 300, no. 9, pp. 1027-1037, 2008.

[75] F. G. Coelho, T. M. Vital, A. M. Stein et al., “Acute aerobic exercise increases brain-derived neurotrophic factor levels in elderly with Alzheimer's disease," Journal of Alzheimer's Disease, vol. 39, no. 2, pp. 401-408, 2014.

[76] H. S. Phillips, J. M. Hains, M. Armanini, G. R. Laramee, S. A. Johnson, and J. W. Winslow, "BDNF mRNA is decreased in the hippocampus of individuals with Alzheimer's disease," Neuron, vol. 7, no. 5, pp. 695-702, 1991.

[77] S. Y. Yau, J. Gil-Mohapel, B. R. Christie, and K. F. So, "Physical exercise-induced adult neurogenesis: a good 
strategy to prevent cognitive decline in neurodegenerative diseases?" BioMed Research International, vol. 2014, Article ID 403120, 20 pages, 2014.

[78] K. D. Langdon and D. Corbett, "Improved working memory following novel combinations of physical and cognitive activity," Neurorehabilitation and Neural Repair, vol. 26, no. 5, pp. 523-532, 2012.

[79] S. Vaynman, Z. Ying, and F. Gomez-Pinilla, "Exercise induces BDNF and synapsin I to specific hippocampal subfields," Journal of Neuroscience Research, vol. 76, no. 3, pp. 356-362, 2004.

[80] R. S. Duman and L. M. Monteggia, "A neurotrophic model for stress-related mood disorders," Biological Psychiatry, vol. 59, no. 12, pp. 1116-1127, 2006.

[81] Y. Lu, K. Christian, and B. Lu, "BDNF: a key regulator for protein synthesis-dependent LTP and long-term memory?" Neurobiology of Learning and Memory, vol. 89, no. 3, pp. 312-323, 2008.

[82] S. L. Patterson, "Immune dysregulation and cognitive vulnerability in the aging brain: interactions of microglia, IL-1beta, BDNF and synaptic plasticity," Neuropharmacology, vol. 96, Part A, pp. 11-18, 2015.

[83] V. Krishnan and E. J. Nestler, "The molecular neurobiology of depression," Nature, vol. 455, no. 7215, pp. 894-902, 2008.

[84] W. Deng, J. B. Aimone, and F. H. Gage, "New neurons and new memories: how does adult hippocampal neurogenesis affect learning and memory?" Nature Reviews. Neuroscience, vol. 11, no. 5, pp. 339-350, 2010.

[85] J. Altman and G. D. Das, "Post-natal origin of microneurones in the rat brain," Nature, vol. 207, no. 5000, pp. 953956, 1965.

[86] C. Schmidt-Hieber, P. Jonas, and J. Bischofberger, "Enhanced synaptic plasticity in newly generated granule cells of the adult hippocampus," Nature, vol. 429, no. 6988, pp. 184$187,2004$.

[87] C. Vivar and H. van Praag, "Functional circuits of new neurons in the dentate gyrus," Front Neural Circuits, vol. 7, p. 15, 2013.

[88] G. Kronenberg, A. Bick-Sander, E. Bunk, C. Wolf, D. Ehninger, and G. Kempermann, "Physical exercise prevents age-related decline in precursor cell activity in the mouse dentate gyrus," Neurobiology of Aging, vol. 27, no. 10, pp. 1505-1513, 2006.

[89] G. Kronenberg, K. Reuter, B. Steiner et al., "Subpopulations of proliferating cells of the adult hippocampus respond differently to physiologic neurogenic stimuli," The Journal of Comparative Neurology, vol. 467, no. 4, pp. 455-463, 2003.

[90] H. van Praag, G. Kempermann, and F. H. Gage, "Running increases cell proliferation and neurogenesis in the adult mouse dentate gyrus," Nature Neuroscience, vol. 2, no. 3, pp. 266-270, 1999.

[91] G. Kempermann, "The neurogenic reserve hypothesis: what is adult hippocampal neurogenesis good for?" Trends in Neurosciences, vol. 31, no. 4, pp. 163-169, 2008.

[92] G. Kempermann and F. H. Gage, "Experience-dependent regulation of adult hippocampal neurogenesis: effects of long-term stimulation and stimulus withdrawal," Hippocampus, vol. 9, no. 3, pp. 321-332, 1999.

[93] A. C. Pereira, D. E. Huddleston, A. M. Brickman et al., "An in vivo correlate of exercise-induced neurogenesis in the adult dentate gyrus," Proceedings of the National Academy of Sciences of the United States of America, vol. 104, no. 13, pp. 5638-5643, 2007.

[94] K. I. Erickson, M. W. Voss, R. S. Prakash et al., "Exercise training increases size of hippocampus and improves memory," Proceedings of the National Academy of Sciences of the United States of America, vol. 108, no. 7, pp. 30173022, 2011.

[95] L. F. ten Brinke, N. Bolandzadeh, L. S. Nagamatsu et al., "Aerobic exercise increases hippocampal volume in older women with probable mild cognitive impairment: a 6-month randomised controlled trial," British Journal of Sports Medicine, vol. 49, no. 4, pp. 248-254, 2015.

[96] O. Lazarov and C. Hollands, "Hippocampal neurogenesis: learning to remember," Progress in Neurobiology, vol. 138140, pp. 1-18, 2016.

[97] M. Gleeson, N. C. Bishop, D. J. Stensel, M. R. Lindley, S. S. Mastana, and M. A. Nimmo, "The anti-inflammatory effects of exercise: mechanisms and implications for the prevention and treatment of disease," Nature Reviews. Immunology, vol. 11, no. 9, pp. 607-615, 2011.

[98] K. J. Stewart, "Exercise training and the cardiovascular consequences of type 2 diabetes and hypertension: plausible mechanisms for improving cardiovascular health," Jama, vol. 288, no. 13, pp. 1622-1631, 2002.

[99] L. H. Colbert, M. Visser, E. M. Simonsick et al., "Physical activity, exercise, and inflammatory markers in older adults: findings from the health, aging and body composition study," Journal of the American Geriatrics Society, vol. 52, no. 7, pp. 1098-1104, 2004.

[100] J. T. Venjatraman and G. Fernandes, "Exercise, immunity and aging," Aging (Milano), vol. 9, no. 1-2, pp. 42-56, 1997.

[101] M. L. Kohut, D. A. McCann, D. W. Russell et al., "Aerobic exercise, but not flexibility/resistance exercise, reduces serum IL-18, CRP, and IL-6 independent of beta-blockers, BMI, and psychosocial factors in older adults," Brain, Behavior, and Immunity, vol. 20, no. 3, pp. 201-209, 2006.

[102] J. M. DiPenta, J. G. Johnson, and R. J. Murphy, "Natural killer cells and exercise training in the elderly: a review," Canadian Journal of Applied Physiology, vol. 29, no. 4, pp. 419-443, 2004.

[103] J. A. Woods, M. A. Ceddia, B. W. Wolters, J. K. Evans, Q. Lu, and E. McAuley, "Effects of 6 months of moderate aerobic exercise training on immune function in the elderly," Mechanisms of Ageing and Development, vol. 109, no. 1, pp. 1-19, 1999.

[104] M. A. Febbraio and B. K. Pedersen, "Muscle-derived interleukin-6: mechanisms for activation and possible biological roles," The FASEB Journal, vol. 16, no. 11, pp. 1335-1347, 2002.

[105] G. Ravaglia, P. Forti, F. Maioli et al., "Blood inflammatory markers and risk of dementia: the Conselice Study of Brain Aging," Neurobiology of Aging, vol. 28, no. 12, pp. 18101820, 2007.

[106] R. M. Daly, S. L. O'Connell, N. L. Mundell, C. A. Grimes, D. W. Dunstan, and C. A. Nowson, "Protein-enriched diet, with the use of lean red meat, combined with progressive resistance training enhances lean tissue mass and muscle strength and reduces circulating IL-6 concentrations in elderly women: a cluster randomized controlled trial," The American Journal of Clinical Nutrition, vol. 99, no. 4, pp. 899-910, 2014. 
[107] R. Burger, "Impact of interleukin-6 in hematological malignancies," Transfusion Medicine and Hemotherapy, vol. 40, no. 5, pp. 336-343, 2013.

[108] B. T. Baune, G. Ponath, J. Golledge et al., "Association between IL-8 cytokine and cognitive performance in an elderly general population-the MEMO-Study," Neurobiology of Aging, vol. 29, no. 6, pp. 937-944, 2008.

[109] D. C. Nieman, "Current perspective on exercise immunology," Current Sports Medicine Reports, vol. 2, no. 5, pp. 239-242, 2003.

[110] K. Ostrowski, T. Rohde, S. Asp, P. Schjerling, and B. K. Pedersen, "Chemokines are elevated in plasma after strenuous exercise in humans," European Journal of Applied Physiology, vol. 84, no. 3, pp. 244-245, 2001.

[111] K. Yasojima, C. Schwab, E. G. McGeer, and P. L. McGeer, "Human neurons generate C-reactive protein and amyloid P: upregulation in Alzheimer's disease," Brain Research, vol. 887 , no. 1 , pp. $80-89,2000$.

[112] B. T. Bi, H. B. Lin, Y. F. Cheng et al., "Promotion of beta-amyloid production by C-reactive protein and its implications in the early pathogenesis of Alzheimer's disease," Neurochemistry International, vol. 60, no. 3, pp. 257266, 2012.

[113] A. Michigan, T. V. Johnson, and V. A. Master, "Review of the relationship between C-reactive protein and exercise," Molecular Diagnosis \& Therapy, vol. 15, no. 5, pp. 265-275, 2011.

[114] R. J. Guerreiro, I. Santana, J. M. Bras, B. Santiago, A. Paiva, and C. Oliveira, "Peripheral inflammatory cytokines as biomarkers in Alzheimer's disease and mild cognitive impairment," Neurodegenerative Diseases, vol. 4, no. 6, pp. 406-412, 2007.

[115] K. A. Frankola, N. H. Greig, W. Luo, and D. Tweedie, "Targeting TNF-alpha to elucidate and ameliorate neuroinflammation in neurodegenerative diseases," CNS \& Neurological Disorders Drug Targets, vol. 10, no. 3, pp. 391-403, 2011.

[116] V. Ambarish, S. Chandrashekara, and K. P. Suresh, "Moderate regular exercises reduce inflammatory response for physical stress," Indian Journal of Physiology and Pharmacology, vol. 56, no. 1, pp. 7-14, 2012.

[117] H. E. Ploeger, T. Takken, M. H. de Greef, and B. W. Timmons, "The effects of acute and chronic exercise on inflammatory markers in children and adults with a chronic inflammatory disease: a systematic review," Exercise Immunology Review, vol. 15, pp. 6-41, 2009.

[118] N. Mathur and B. K. Pedersen, "Exercise as a mean to control low-grade systemic inflammation," Mediators of Inflammation, vol. 2008, Article ID 109502, 6 pages, 2008.

[119] K. M. Beavers, T. E. Brinkley, and B. J. Nicklas, "Effect of exercise training on chronic inflammation," Clinica Chimica Acta, vol. 411, no. 11-12, pp. 785-793, 2010.

[120] T. Archer, A. Fredriksson, E. Schutz, and R. M. Kostrzewa, "Influence of physical exercise on neuroimmunological functioning and health: aging and stress," Neurotoxicity Research, vol. 20, no. 1, pp. 69-83, 2011.

[121] N. E. Thomas and D. R. Williams, "Inflammatory factors, physical activity, and physical fitness in young people," Scandinavian Journal of Medicine \& Science in Sports, vol. 18, no. 5, pp. 543-556, 2008.

[122] M. V. Fedewa, E. D. Hathaway, and C. L. Ward-Ritacco, "Effect of exercise training on C-reactive protein: a systematic review and meta-analysis of randomised and non-randomised controlled trials," British Journal of Sports Medicine, vol. 51, 2016.

[123] S. M. Ryan and Y. M. Nolan, "Neuroinflammation negatively affects adult hippocampal neurogenesis and cognition: can exercise compensate?" Neuroscience and Biobehavioral Reviews, vol. 61, pp. 121-131, 2016.

[124] J. C. Pruessner, K. Dedovic, N. Khalili-Mahani et al., "Deactivation of the limbic system during acute psychosocial stress: evidence from positron emission tomography and functional magnetic resonance imaging studies," Biological Psychiatry, vol. 63, no. 2, pp. 234-240, 2008.

[125] J. A. Rosenkranz, D. M. Buffalari, and A. A. Grace, "Opposing influence of basolateral amygdala and footshock stimulation on neurons of the central amygdala," Biological Psychiatry, vol. 59, no. 9, pp. 801-811, 2006.

[126] J. B. Rosen, M. S. Fanselow, S. L. Young, M. Sitcoske, and S. Maren, "Immediate-early gene expression in the amygdala following footshock stress and contextual fear conditioning," Brain Research, vol. 796, no. 1-2, pp. 132-142, 1998.

[127] D. Gupta and J. E. Morley, "Hypothalamic-pituitary-adrenal (HPA) axis and aging," Comprehensive Physiology, vol. 4, no. 4, pp. 1495-1510, 2014.

[128] E. S. Brown, A. J. Rush, and B. S. McEwen, "Hippocampal remodeling and damage by corticosteroids: implications for mood disorders," Neuropsychopharmacology, vol. 21, no. 4, pp. 474-484, 1999.

[129] R. M. Sapolsky, H. Uno, C. S. Rebert, and C. E. Finch, "Hippocampal damage associated with prolonged glucocorticoid exposure in primates," The Journal of Neuroscience, vol. 10, no. 9, pp. 2897-2902, 1990.

[130] H. K. Manji, J. A. Quiroz, J. Sporn et al., "Enhancing neuronal plasticity and cellular resilience to develop novel, improved therapeutics for difficult-to-treat depression," Biological Psychiatry, vol. 53, no. 8, pp. 707-742, 2003.

[131] C. M. Pariante and S. L. Lightman, "The HPA axis in major depression: classical theories and new developments," Trends in Neurosciences, vol. 31, no. 9, pp. 464-468, 2008.

[132] C. L. Raison, L. Capuron, and A. H. Miller, "Cytokines sing the blues: inflammation and the pathogenesis of depression," Trends in Immunology, vol. 27, no. 1, pp. 24-31, 2006.

[133] L. Robert and J. Labat-Robert, "Stress in biology and medicine, role in aging," Pathologie Biologie, vol. 63, no. 45, pp. 230-234, 2015.

[134] A. H. Miller, C. M. Pariante, and B. D. Pearce, "Effects of cytokines on glucocorticoid receptor expression and function. Glucocorticoid resistance and relevance to depression," Advances in Experimental Medicine and Biology, vol. 461, pp. 107-116, 1999.

[135] C. Otte, S. Hart, T. C. Neylan, C. R. Marmar, K. Yaffe, and D. C. Mohr, "A meta-analysis of cortisol response to challenge in human aging: importance of gender," Psychoneuroendocrinology, vol. 30, no. 1, pp. 80-91, 2005.

[136] E. Van Cauter, "Diurnal and ultradian rhythms in human endocrine function: a minireview," Hormone Research, vol. 34, no. 2, pp. 45-53, 1990.

[137] E. R. de Kloet, M. Joels, and F. Holsboer, "Stress and the brain: from adaptation to disease," Nature Reviews. Neuroscience, vol. 6, no. 6, pp. 463-475, 2005.

[138] A. Machado, A. J. Herrera, R. M. de Pablos et al., "Chronic stress as a risk factor for Alzheimer's disease," Reviews in the Neurosciences, vol. 25, no. 6, pp. 785-804, 2014. 
[139] N. C. Gassen, G. P. Chrousos, E. B. Binder, and A. S. Zannas, "Life stress, glucocorticoid signaling, and the aging epigenome: implications for aging-related diseases," Neuroscience and Biobehavioral Reviews, vol. 74, 2016.

[140] F. Holsboer, "The corticosteroid receptor hypothesis of depression," Neuropsychopharmacology, vol. 23, no. 5, pp. 477-501, 2000.

[141] M. Belvederi Murri, D. Prestia, V. Mondelli et al., "The HPA axis in bipolar disorder: systematic review and meta-analysis," Psychoneuroendocrinology, vol. 63, pp. 327-342, 2016.

[142] T. Steckler, F. Holsboer, and J. M. Reul, "Glucocorticoids and depression," Baillière's Best Practice \& Research. Clinical Endocrinology \& Metabolism, vol. 13, no. 4, pp. 597-614, 1999.

[143] U. M. Nater, L. S. Youngblood, J. F. Jones et al., "Alterations in diurnal salivary cortisol rhythm in a population-based sample of cases with chronic fatigue syndrome," Psychosomatic Medicine, vol. 70, no. 3, pp. 298-305, 2008.

[144] A. S. Karlamangla, E. M. Friedman, T. E. Seeman, R. S. Stawksi, and D. M. Almeida, "Daytime trajectories of cortisol: demographic and socioeconomic differences-findings from the National Study of Daily Experiences," Psychoneuroendocrinology, vol. 38, no. 11, pp. 2585-2597, 2013.

[145] N. O. Dmitrieva, D. M. Almeida, J. Dmitrieva, E. Loken, and C. F. Pieper, "A day-centered approach to modeling cortisol: diurnal cortisol profiles and their associations among U.S. adults," Psychoneuroendocrinology, vol. 38, no. 10 , pp. 2354-2365, 2013.

[146] U. M. Nater, C. A. Hoppmann, and S. B. Scott, "Diurnal profiles of salivary cortisol and alpha-amylase change across the adult lifespan: evidence from repeated daily life assessments," Psychoneuroendocrinology, vol. 38, no. 12, pp. 3167-3171, 2013.

[147] E. K. Adam, L. C. Hawkley, B. M. Kudielka, and J. T. Cacioppo, "Day-to-day dynamics of experience-cortisol associations in a population-based sample of older adults," Proceedings of the National Academy of Sciences of the United States of America, vol. 103, no. 45, pp. 17058-17063, 2006.

[148] R. Sapolsky, "Sick of poverty," Scientific American, vol. 293, no. 6, pp. 92-99, 2005.

[149] G. E. Miller, E. Chen, and E. S. Zhou, "If it goes up, must it come down? Chronic stress and the hypothalamicpituitary-adrenocortical axis in humans," Psychological Bulletin, vol. 133, no. 1, pp. 25-45, 2007.

[150] K. Wingenfeld and O. T. Wolf, "Stress, memory, and the hippocampus," Frontiers of Neurology and Neuroscience, vol. 34, pp. 109-120, 2014.

[151] H. Johar, R. T. Emeny, M. Bidlingmaier et al., "Blunted diurnal cortisol pattern is associated with frailty: a crosssectional study of 745 participants aged 65 to 90 years," The Journal of Clinical Endocrinology and Metabolism, vol. 99, no. 3, pp. E464-E468, 2014.

[152] R. Noordam, S. W. Jansen, A. A. Akintola et al., "Familial longevity is marked by lower diurnal salivary cortisol levels: the Leiden longevity study," PloS One, vol. 7, no. 2, article e31166, 2012.

[153] B. K. Pedersen and B. Saltin, "Exercise as medicine - evidence for prescribing exercise as therapy in 26 different chronic diseases," Scandinavian Journal of Medicine \& Science in Sports, vol. 25, Supplement 3, pp. 1-72, 2015.

[154] S. N. Blair, M. J. LaMonte, and M. Z. Nichaman, "The evolution of physical activity recommendations: how much is enough?" The American Journal of Clinical Nutrition, vol. 79, no. 5, pp. 913S-920S, 2004.

[155] H. E. Webb, D. S. Rosalky, S. E. Tangsilsat, K. A. McLeod, E. O. Acevedo, and B. Wax, "Aerobic fitness affects cortisol responses to concurrent challenges," Medicine and Science in Sports and Exercise, vol. 45, no. 2, pp. 379-386, 2013.

[156] A. M. Stranahan, K. Lee, and M. P. Mattson, "Contributions of impaired hippocampal plasticity and neurodegeneration to age-related deficits in hormonal pulsatility," Ageing Research Reviews, vol. 7, no. 3, pp. 164-176, 2008.

[157] S. J. Lupien, M. de Leon, S. de Santi et al., "Cortisol levels during human aging predict hippocampal atrophy and memory deficits," Nature Neuroscience, vol. 1, no. 1, pp. 6973, 1998 .

[158] D. P. Devanand, G. Pradhaban, X. Liu et al., "Hippocampal and entorhinal atrophy in mild cognitive impairment: prediction of Alzheimer disease," Neurology, vol. 68, no. 11, pp. 828-836, 2007.

[159] L. G. Apostolova, R. A. Dutton, I. D. Dinov et al., "Conversion of mild cognitive impairment to Alzheimer disease predicted by hippocampal atrophy maps," Archives of Neurology, vol. 63, no. 5, pp. 693-699, 2006.

[160] H. Makizako, T. Liu-Ambrose, H. Shimada et al., "Moderateintensity physical activity, hippocampal volume, and memory in older adults with mild cognitive impairment," The Journals of Gerontology. Series a, Biological Sciences and Medical Sciences, vol. 70, no. 4, pp. 480-486, 2015.

[161] C. S. Woolley, E. Gould, and B. S. McEwen, "Exposure to excess glucocorticoids alters dendritic morphology of adult hippocampal pyramidal neurons," Brain Research, vol. 531, no. 1-2, pp. 225-231, 1990.

[162] V. A. Redila and B. R. Christie, "Exercise-induced changes in dendritic structure and complexity in the adult hippocampal dentate gyrus," Neuroscience, vol. 137, no. 4, pp. 12991307, 2006.

[163] H. Sies, "Oxidative stress: a concept in redox biology and medicine," Redox Biology, vol. 4, pp. 180-183, 2015.

[164] P. H. Chan, "Reactive oxygen radicals in signaling and damage in the ischemic brain," Journal of Cerebral Blood Flow and Metabolism, vol. 21, no. 1, pp. 2-14, 2001.

[165] R. A. Floyd and J. M. Carney, "Free radical damage to protein and DNA: mechanisms involved and relevant observations on brain undergoing oxidative stress," Annals of Neurology, vol. 32 Supplement, pp. S22-S27, 1992.

[166] R. A. Floyd, "Antioxidants, oxidative stress, and degenerative neurological disorders," Proceedings of the Society for Experimental Biology and Medicine, vol. 222, no. 3, pp. 236-245, 1999.

[167] Z. Radak, H. Y. Chung, and S. Goto, "Systemic adaptation to oxidative challenge induced by regular exercise," Free Radical Biology \& Medicine, vol. 44, no. 2, pp. 153-159, 2008.

[168] C. R. Frasier, F. Moukdar, H. D. Patel et al., "Redoxdependent increases in glutathione reductase and exercise preconditioning: role of NADPH oxidase and mitochondria," Cardiovascular Research, vol. 98, no. 1, pp. 47-55, 2013.

[169] C. Leeuwenburgh and J. W. Heinecke, "Oxidative stress and antioxidants in exercise," Current Medicinal Chemistry, vol. 8, no. 7, pp. 829-838, 2001.

[170] T. Ngandu, E. von Strauss, E. L. Helkala et al., "Education and dementia: what lies behind the association?" Neurology, vol. 69, no. 14, pp. 1442-1450, 2007. 
[171] Y. Stern, B. Gurland, T. K. Tatemichi, M. X. Tang, D. Wilder, and R. Mayeux, "Influence of education and occupation on the incidence of Alzheimer's disease," Jama, vol. 271, no. 13, pp. 1004-1010, 1994.

[172] H. X. Wang, D. R. Gustafson, M. Kivipelto et al., "Education halves the risk of dementia due to apolipoprotein epsilon4 allele: a collaborative study from the Swedish brain power initiative," Neurobiology of Aging, vol. 33, no. 5, pp. 1007.e1-1007.e7, 2012.

[173] C. Ferrari, B. Nacmias, S. Bagnoli et al., "Imaging and cognitive reserve studies predict dementia in presymptomatic Alzheimer's disease subjects," Neurodegenerative Diseases, vol. 13, no. 2-3, pp. 157-159, 2014.

[174] E. C. C. Members, C. Brayne, P. G. Ince et al., "Education, the brain and dementia: neuroprotection or compensation?" Brain, vol. 133, Part 8, pp. 2210-2216, 2010.

[175] M. Mortamais, F. Portet, A. M. Brickman et al., "Education modulates the impact of white matter lesions on the risk of mild cognitive impairment and dementia," The American Journal of Geriatric Psychiatry, vol. 22, no. 11, pp. 13361345, 2014.

[176] M. Gatz, C. A. Prescott, and N. L. Pedersen, "Lifestyle risk and delaying factors," Alzheimer Disease and Associated Disorders, vol. 20, no. 3, Supplement 2, pp. S84-S88, 2006.

[177] C. Schooler and M. S. Mulatu, "The reciprocal effects of leisure time activities and intellectual functioning in older people: a longitudinal analysis," Psychology and Aging, vol. 16, no. 3, pp. 466-482, 2001.

[178] M. L. Kohn and C. Schooler, "The reciprocal effects of the substantive complexity of work and intellectual flexibility: a longitudinal assessment," American Journal of Sociology, vol. 84, pp. 24-52, 1978.

[179] E. L. Smart, A. J. Gow, and I. J. Deary, "Occupational complexity and lifetime cognitive abilities," Neurology, vol. 83, no. 24, pp. 2285-2291, 2014.

[180] M. Crowe, R. Andel, N. L. Pedersen, B. Johansson, and M. Gatz, "Does participation in leisure activities lead to reduced risk of Alzheimer's disease? A prospective study of Swedish twins," The Journals of Gerontology. Series B, Psychological Sciences and Social Sciences, vol. 58, no. 5, pp. 249-255, 2003.

[181] M. E. Paggi, D. Jopp, and C. Hertzog, "The importance of leisure activities in the relationship between physical health and well-being in a life span sample," Gerontology, vol. 62, no. 4, pp. 450-458, 2016.

[182] M. B. Mitchell, C. R. Cimino, A. Benitez et al., "Cognitively stimulating activities: effects on cognition across four studies with up to 21 years of longitudinal data," Journal of Aging Research, vol. 2012, Article ID 461592, 12 pages, 2012.

[183] R. S. Wilson, L. L. Barnes, K. R. Krueger, G. Hoganson, J. L. Bienias, and D. A. Bennett, "Early and late life cognitive activity and cognitive systems in old age," Journal of the International Neuropsychological Society, vol. 11, no. 4, pp. 400-407, 2005.

[184] K. Hotting and B. Roder, "Beneficial effects of physical exercise on neuroplasticity and cognition," Neuroscience and Biobehavioral Reviews, vol. 37, no. 9, Part B, pp. 22432257, 2013.

[185] Y. Stern, "Cognitive reserve in ageing and Alzheimer's disease," Lancet Neurology, vol. 11, no. 11, pp. 10061012, 2012.
[186] A. M. Tucker and Y. Stern, "Cognitive reserve in aging," Current Alzheimer Research, vol. 8, no. 4, pp. 354-360, 2011.

[187] D. E. Sorman, A. Sundstrom, M. Ronnlund, R. Adolfsson, and L. G. Nilsson, "Leisure activity in old age and risk of dementia: a 15-year prospective study," The Journals of Gerontology. Series B, Psychological Sciences and Social Sciences, vol. 69, no. 4, pp. 493-501, 2014.

[188] A. Karp, S. Paillard-Borg, H. X. Wang, M. Silverstein, B. Winblad, and L. Fratiglioni, "Mental, physical and social components in leisure activities equally contribute to decrease dementia risk," Dementia and Geriatric Cognitive Disorders, vol. 21, no. 2, pp. 65-73, 2006.

[189] D. Perani and J. Abutalebi, "Bilingualism, dementia, cognitive and neural reserve," Current Opinion in Neurology, vol. 28, no. 6, pp. 618-625, 2015.

[190] T. H. Bak, M. R. Long, M. Vega-Mendoza, and A. Sorace, "Novelty, challenge, and practice: the impact of intensive language learning on attentional functions," PloS One, vol. 11, no. 4, article e $0153485,2016$.

[191] N. Scarmeas, G. Levy, M. X. Tang, J. Manly, and Y. Stern, "Influence of leisure activity on the incidence of Alzheimer's disease," Neurology, vol. 57, no. 12, pp. 2236-2242, 2001.

[192] H. X. Wang, A. Karp, B. Winblad, and L. Fratiglioni, "Latelife engagement in social and leisure activities is associated with a decreased risk of dementia: a longitudinal study from the Kungsholmen project," American Journal of Epidemiology, vol. 155, no. 12, pp. 1081-1087, 2002.

[193] T. Bak, "Language lessons to help protect against dementia," $B M J$, vol. 354, p. i5039, 2016.

[194] J. Verghese, R. B. Lipton, M. J. Katz et al., "Leisure activities and the risk of dementia in the elderly," The New England Journal of Medicine, vol. 348, no. 25, pp. 2508-2516, 2003.

[195] P. W. Schofield, G. Logroscino, H. F. Andrews, S. Albert, and Y. Stern, "An association between head circumference and Alzheimer's disease in a population-based study of aging and dementia," Neurology, vol. 49, no. 1, pp. 30-37, 1997.

[196] R. Katzman, R. Terry, R. DeTeresa et al., "Clinical, pathological, and neurochemical changes in dementia: a subgroup with preserved mental status and numerous neocortical plaques," Annals of Neurology, vol. 23, no. 2, pp. 138144, 1988.

[197] M. J. Valenzuela, P. Sachdev, W. Wen, X. Chen, and H. Brodaty, "Lifespan mental activity predicts diminished rate of hippocampal atrophy," PloS One, vol. 3, no. 7, article e2598, 2008.

[198] Y. Stern, “Cognitive reserve," Neuropsychologia, vol. 47, no. 10, pp. 2015-2028, 2009.

[199] Y. Stern, "What is cognitive reserve? Theory and Research Application of the Reserve Concept," Journal of the International Neuropsychological Society, vol. 8, no. 3, pp. 448-460, 2002.

[200] A. F. Kramer, L. Bherer, S. J. Colcombe, W. Dong, and W. T. Greenough, "Environmental influences on cognitive and brain plasticity during aging," The Journals of Gerontology. Series A, Biological Sciences and Medical Sciences, vol. 59, no. 9, pp. M940-M957, 2004.

[201] J. Brown, C. M. Cooper-Kuhn, G. Kempermann et al., "Enriched environment and physical activity stimulate hippocampal but not olfactory bulb neurogenesis," The European Journal of Neuroscience, vol. 17, no. 10, pp. 2042-2046, 2003. 
[202] G. Kempermann, D. Gast, and F. H. Gage, "Neuroplasticity in old age: sustained fivefold induction of hippocampal neurogenesis by long-term environmental enrichment," Annals of Neurology, vol. 52, no. 2, pp. 135-143, 2002.

[203] H. van Praag, G. Kempermann, and F. H. Gage, "Neural consequences of environmental enrichment," Nature Reviews. Neuroscience, vol. 1, no. 3, pp. 191-198, 2000.

[204] E. Castren, F. Zafra, H. Thoenen, and D. Lindholm, "Light regulates expression of brain-derived neurotrophic factor mRNA in rat visual cortex," Proceedings of the National Academy of Sciences of the United States of America, vol. 89, no. 20, pp. 9444-9448, 1992.

[205] H. Okazawa, M. Murata, M. Watanabe, M. Kamei, and I. Kanazawa, "Dopaminergic stimulation up-regulates the in vivo expression of brain-derived neurotrophic factor (BDNF) in the striatum," FEBS Letters, vol. 313, no. 2, pp. 138-142, 1992.

[206] K. M. Frick, N. A. Stearns, J. Y. Pan, and J. Berger-Sweeney, "Effects of environmental enrichment on spatial memory and neurochemistry in middle-aged mice," Learning \& Memory, vol. 10, no. 3, pp. 187-198, 2003.

[207] A. E. Gaffey, C. S. Bergeman, L. A. Clark, and M. M. Wirth, "Aging and the HPA axis: stress and resilience in older adults," Neuroscience and Biobehavioral Reviews, vol. 68, pp. 928-945, 2016.

[208] S. M. Golant, "Residential normalcy and the enriched coping repertoires of successfully aging older adults," Gerontologist, vol. 55, no. 1, pp. 70-82, 2015.

[209] Z. Hildon, S. M. Montgomery, D. Blane, R. D. Wiggins, and G. Netuveli, "Examining resilience of quality of life in the face of health-related and psychosocial adversity at older ages: what is "right" about the way we age?" Gerontologist, vol. 50, no. 1, pp. 36-47, 2010.

[210] G. Netuveli, R. D. Wiggins, S. M. Montgomery, Z. Hildon, and D. Blane, "Mental health and resilience at older ages: bouncing back after adversity in the British Household Panel Survey," Journal of Epidemiology and Community Health, vol. 62, no. 11, pp. 987-991, 2008.

[211] P. A. Gooding, A. Hurst, J. Johnson, and N. Tarrier, "Psychological resilience in young and older adults," International Journal of Geriatric Psychiatry, vol. 27, no. 3, pp. 262-270, 2012.

[212] E. Hamarat, D. Thompson, F. Aysan, D. Steele, K. Matheny, and C. Simons, "Age differences in coping resources and satisfaction with life among middle-aged, young-old, and oldest-old adults," The Journal of Genetic Psychology, vol. 163, no. 3, pp. 360-367, 2002.

[213] D. V. Jeste, G. N. Savla, W. K. Thompson et al., "Association between older age and more successful aging: critical role of resilience and depression," The American Journal of Psychiatry, vol. 170, no. 2, pp. 188-196, 2013.

[214] A. J. Lamond, C. A. Depp, M. Allison et al., "Measurement and predictors of resilience among community-dwelling older women," Journal of Psychiatric Research, vol. 43, no. 2, pp. 148-154, 2008.

[215] J. L. Smith and L. Hollinger-Smith, "Savoring, resilience, and psychological well-being in older adults," Aging \& Mental Health, vol. 19, no. 3, pp. 192-200, 2015.

[216] E. A. L. Stine-Morrow and H. Chui, "Chapter 5 cognitive resilience in adulthood annual review of gerontology and geriatrics," Annual review of gerontology and geriatrics, vol. 32, no. 1, pp. 93-114, 2012.

[217] L. Fratiglioni, S. Paillard-Borg, and B. Winblad, "An active and socially integrated lifestyle in late life might protect against dementia," Lancet Neurology, vol. 3, no. 6, pp. 343-353, 2004.

[218] B. Shatenstein, P. Barberger-Gateau, and P. Mecocci, "Prevention of age-related cognitive decline: which strategies, when, and for whom?" Journal of Alzheimer's Disease, vol. 48, no. 1, pp. 35-53, 2015.

[219] K. C. Fox, S. Nijeboer, M. L. Dixon et al., "Is meditation associated with altered brain structure? A systematic review and meta-analysis of morphometric neuroimaging in meditation practitioners," Neuroscience and Biobehavioral Reviews, vol. 43, pp. 48-73, 2014.

[220] A. Mohan, A. J. Roberto, A. Mohan et al., "The significance of the default mode network (DMN) in neurological and neuropsychiatric disorders: a review," The Yale Journal of Biology and Medicine, vol. 89, no. 1, pp. 49-57, 2016.

[221] H. J. Li, X. H. Hou, H. H. Liu, C. L. Yue, Y. He, and X. N. Zuo, "Toward systems neuroscience in mild cognitive impairment and Alzheimer's disease: a meta-analysis of $75 \mathrm{fMRI}$ studies," Human Brain Mapping, vol. 36, no. 3, pp. 1217-1232, 2015.

[222] Y. Y. Tang, B. K. Holzel, and M. I. Posner, "The neuroscience of mindfulness meditation," Nature Reviews. Neuroscience, vol. 16, no. 4, pp. 213-225, 2015.

[223] A. Chiesa and A. Serretti, "Mindfulness-based stress reduction for stress management in healthy people: a review and meta-analysis," Journal of Alternative and Complementary Medicine, vol. 15, no. 5, pp. 593-600, 2009.

[224] J. D. Creswell, L. E. Pacilio, E. K. Lindsay, and K. W. Brown, "Brief mindfulness meditation training alters psychological and neuroendocrine responses to social evaluative stress," Psychoneuroendocrinology, vol. 44, pp. 1-12, 2014.

[225] R. Jevning, A. F. Wilson, and J. M. Davidson, "Adrenocortical activity during meditation," Hormones and Behavior, vol. 10, no. 1, pp. 54-60, 1978.

[226] M. Martin, L. Clare, A. M. Altgassen, M. H. Cameron, and F. Zehnder, "Cognition-based interventions for healthy older people and people with mild cognitive impairment," Cochrane Database of Systematic Reviews, vol. 1, no. 1, p. CD006220, 2011.

[227] M. J. Chandler, A. C. Parks, M. Marsiske, L. J. Rotblatt, and G. E. Smith, "Everyday impact of cognitive interventions in mild cognitive impairment: a systematic review and meta-analysis," Neuropsychology Review, vol. 26, no. 3, pp. 225-251, 2016.

[228] S. L. Willis, S. L. Tennstedt, M. Marsiske et al., "Long-term effects of cognitive training on everyday functional outcomes in older adults," Jama, vol. 296, no. 23, pp. 2805-2814, 2006.

[229] F. Gomez-Pinilla and E. Tyagi, "Diet and cognition: interplay between cell metabolism and neuronal plasticity," Current Opinion in Clinical Nutrition and Metabolic Care, vol. 16, no. 6, pp. 726-733, 2013.

[230] K. Dasuri, L. Zhang, and J. N. Keller, "Oxidative stress, neurodegeneration, and the balance of protein degradation and protein synthesis," Free Radical Biology \& Medicine, vol. 62, pp. 170-185, 2013.

[231] M. P. Mattson, M. Gleichmann, and A. Cheng, "Mitochondria in neuroplasticity and neurological disorders," Neuron, vol. 60 , no. 5 , pp. $748-766,2008$. 
[232] M. J. Dauncey, "New insights into nutrition and cognitive neuroscience," The Proceedings of the Nutrition Society, vol. 68, no. 4, pp. 408-415, 2009.

[233] R. Agrawal and F. Gomez-Pinilla, "Metabolic syndrome” in the brain: deficiency in omega-3 fatty acid exacerbates dysfunctions in insulin receptor signalling and cognition," The Journal of Physiology, vol. 590, no. 10, pp. 24852499, 2012.

[234] P. W. Caton, N. K. Nayuni, N. Q. Khan, E. G. Wood, and R. Corder, "Fructose induces gluconeogenesis and lipogenesis through a SIRT1-dependent mechanism," The Journal of Endocrinology, vol. 208, no. 3, pp. 273-283, 2011.

[235] R. Agrawal, E. Tyagi, R. Shukla, and C. Nath, "A study of brain insulin receptors, AChE activity and oxidative stress in rat model of ICV STZ induced dementia," Neuropharmacology, vol. 56, no. 4, pp. 779-787, 2009.

[236] L. Flicker, N. T. Lautenschlager, and O. P. Almeida, "Healthy mental ageing," The Journal of the British Menopause Society, vol. 12, no. 3, pp. 92-96, 2006.

[237] J. Lakey-Beitia, R. Berrocal, K. S. Rao, and A. A. Durant, "Polyphenols as therapeutic molecules in Alzheimer's disease through modulating amyloid pathways," Molecular Neurobiology, vol. 51, no. 2, pp. 466-479, 2015.

[238] M. Li, Z. Zhang, D. L. Hill, H. Wang, and R. Zhang, "Curcumin, a dietary component, has anticancer, chemosensitization, and radiosensitization effects by downregulating the MDM2 oncogene through the $\mathrm{PI} 3 \mathrm{~K} / \mathrm{mTOR} /$ ETS2 pathway," Cancer Research, vol. 67, no. 5, pp. 19881996, 2007.

[239] P. Brasnyo, G. A. Molnar, M. Mohas et al., "Resveratrol improves insulin sensitivity, reduces oxidative stress and activates the Akt pathway in type 2 diabetic patients," The British Journal of Nutrition, vol. 106, no. 3, pp. 383-389, 2011.

[240] H. K. Biesalski, "Polyphenols and inflammation: basic interactions," Current Opinion in Clinical Nutrition and Metabolic Care, vol. 10, no. 6, pp. 724-728, 2007.

[241] F. Gomez-Pinilla and T. T. Nguyen, "Natural mood foods: the actions of polyphenols against psychiatric and cognitive disorders," Nutritional Neuroscience, vol. 15, no. 3, pp. 127-133, 2012.

[242] G. Casadesus, B. Shukitt-Hale, H. M. Stellwagen et al., "Modulation of hippocampal plasticity and cognitive behavior by short-term blueberry supplementation in aged rats," Nutritional Neuroscience, vol. 7, no. 5-6, pp. 309-316, 2004.

[243] A. Basli, S. Soulet, N. Chaher et al., "Wine polyphenols: potential agents in neuroprotection," Oxidative Medicine and Cellular Longevity, vol. 2012, Article ID 805762, 14 pages, 2012.

[244] D. Vauzour, "Dietary polyphenols as modulators of brain functions: biological actions and molecular mechanisms underpinning their beneficial effects," Oxidative Medicine and Cellular Longevity, vol. 2012, Article ID 914273, 16 pages, 2012.

[245] B. Shukitt-Hale, F. C. Lau, A. N. Carey et al., "Blueberry polyphenols attenuate kainic acid-induced decrements in cognition and alter inflammatory gene expression in rat hippocampus," Nutritional Neuroscience, vol. 11, no. 4, pp. 172-182, 2008.

[246] A. Y. Sun, Q. Wang, A. Simonyi, and G. Y. Sun, "Botanical phenolics and brain health," Neuromolecular Medicine, vol. 10, no. 4, pp. 259-274, 2008.
[247] C. Rendeiro, J. S. Rhodes, and J. P. Spencer, "The mechanisms of action of flavonoids in the brain: direct versus indirect effects," Neurochemistry International, vol. 89, pp. 126-139, 2015.

[248] T. Murphy, G. P. Dias, and S. Thuret, "Effects of diet on brain plasticity in animal and human studies: mind the gap," Neural Plasticity, vol. 2014, Article ID 563160, 32 pages, 2014.

[249] J. P. Spencer, "The impact of fruit flavonoids on memory and cognition," The British Journal of Nutrition, vol. 104, Supplement 3, pp. S40-S47, 2010.

[250] K. Y. Yoo, J. H. Choi, I. K. Hwang et al., “(-)-Epigallocatechin-3-gallate increases cell proliferation and neuroblasts in the subgranular zone of the dentate gyrus in adult mice," Phytotherapy Research, vol. 24, no. 7, pp. 1065-1070, 2010.

[251] Y. Wang, M. Li, X. Xu, M. Song, H. Tao, and Y. Bai, “Green tea epigallocatechin-3-gallate (EGCG) promotes neural progenitor cell proliferation and sonic hedgehog pathway activation during adult hippocampal neurogenesis," Molecular Nutrition \& Food Research, vol. 56, no. 8, pp. 12921303, 2012.

[252] J. Barbaresko, M. Koch, M. B. Schulze, and U. Nothlings, "Dietary pattern analysis and biomarkers of low-grade inflammation: a systematic literature review," Nutrition Reviews, vol. 71, no. 8, pp. 511-527, 2013.

[253] S. C. Gupta, S. Patchva, W. Koh, and B. B. Aggarwal, "Discovery of curcumin, a component of golden spice, and its miraculous biological activities," Clinical and Experimental Pharmacology \& Physiology, vol. 39, no. 3, pp. 283-299, 2012.

[254] A. B. Kunnumakkara, D. Bordoloi, G. Padmavathi et al., "Curcumin, the golden nutraceutical: multitargeting for multiple chronic diseases," British Journal of Pharmacology, vol. 174, 2016.

[255] S. Giordano, V. Darley-Usmar, and J. Zhang, “Autophagy as an essential cellular antioxidant pathway in neurodegenerative disease," Redox Biology, vol. 2, pp. 82-90, 2014.

[256] P. Maiti, T. C. Hall, L. Paladugu et al., “A comparative study of dietary curcumin, nanocurcumin, and other classical amyloid-binding dyes for labeling and imaging of amyloid plaques in brain tissue of $5 \mathrm{x}$-familial Alzheimer's disease mice," Histochemistry and Cell Biology, vol. 146, no. 5, pp. 609-625, 2016.

[257] M. Okuda, I. Hijikuro, Y. Fujita et al., "Design and synthesis of curcumin derivatives as tau and amyloid beta dual aggregation inhibitors," Bioorganic \& Medicinal Chemistry Letters, vol. 26, no. 20, pp. 5024-5028, 2016.

[258] A. Wu, Z. Ying, and F. Gomez-Pinilla, "Dietary curcumin counteracts the outcome of traumatic brain injury on oxidative stress, synaptic plasticity, and cognition," Experimental Neurology, vol. 197, no. 2, pp. 309-317, 2006.

[259] S. Sharma, Z. Ying, and F. Gomez-Pinilla, "A pyrazole curcumin derivative restores membrane homeostasis disrupted after brain trauma," Experimental Neurology, vol. 226, no. 1, pp. 191-199, 2010.

[260] S. Sharma, Y. Zhuang, Z. Ying, A. Wu, and F. Gomez-Pinilla, "Dietary curcumin supplementation counteracts reduction in levels of molecules involved in energy homeostasis after brain trauma," Neuroscience, vol. 161, no. 4, pp. 1037-1044, 2009.

[261] S. J. Kim, T. G. Son, H. R. Park et al., "Curcumin stimulates proliferation of embryonic neural progenitor cells and neurogenesis in the adult hippocampus," The Journal of Biological Chemistry, vol. 283, no. 21, pp. 14497-14505, 2008. 
[262] C. Zhang, A. Browne, D. Child, and R. E. Tanzi, "Curcumin decreases amyloid-beta peptide levels by attenuating the maturation of amyloid-beta precursor protein," The Journal of Biological Chemistry, vol. 285, no. 37, pp. 28472-28480, 2010.

[263] N. Pandey, J. Strider, W. C. Nolan, S. X. Yan, and J. E. Galvin, "Curcumin inhibits aggregation of alpha-synuclein," Acta Neuropathologica, vol. 115, no. 4, pp. 479-489, 2008.

[264] M. Daval, S. Bedrood, T. Gurlo et al., "The effect of curcumin on human islet amyloid polypeptide misfolding and toxicity," Amyloid, vol. 17, no. 3-4, pp. 118-128, 2010.

[265] M. Garcia-Alloza, L. A. Borrelli, A. Rozkalne, B. T. Hyman, and B. J. Bacskai, "Curcumin labels amyloid pathology in vivo, disrupts existing plaques, and partially restores distorted neurites in an Alzheimer mouse model," Journal of Neurochemistry, vol. 102, no. 4, pp. 1095-1104, 2007.

[266] M. Yao, L. Yang, J. Wang et al., "Neurological recovery and antioxidant effects of curcumin for spinal cord injury in the rat: a network meta-analysis and systematic review," Journal of Neurotrauma, vol. 32, no. 6, pp. 381-391, 2015.

[267] Y. F. Cheng, L. Guo, Y. S. Xie et al., "Curcumin rescues agingrelated loss of hippocampal synapse input specificity of long term potentiation in mice," Neurochemical Research, vol. 38, no. 1, pp. 98-107, 2013.

[268] L. R. Shen, L. D. Parnell, J. M. Ordovas, and C. Q. Lai, "Curcumin and aging," BioFactors, vol. 39, no. 1, pp. 133140, 2013.

[269] K. S. Lee, B. S. Lee, S. Semnani et al., "Curcumin extends life span, improves health span, and modulates the expression of age-associated aging genes in Drosophila melanogaster," Rejuvenation Research, vol. 13, no. 5, pp. 561-570, 2010.

[270] T. P. Ng, P. C. Chiam, T. Lee, H. C. Chua, L. Lim, and E. H. Kua, "Curry consumption and cognitive function in the elderly," American Journal of Epidemiology, vol. 164, no. 9, pp. 898-906, 2006.

[271] L. Baum, C. W. Lam, S. K. Cheung et al., "Six-month randomized, placebo-controlled, double-blind, pilot clinical trial of curcumin in patients with Alzheimer disease," Journal of Clinical Psychopharmacology, vol. 28, no. 1, pp. 110-113, 2008.

[272] K. H. Cox, A. Pipingas, and A. B. Scholey, "Investigation of the effects of solid lipid curcumin on cognition and mood in a healthy older population," Journal of Psychopharmacology, vol. 29, no. 5, pp. 642-651, 2015.

[273] J. W. Daily, M. Yang, and S. Park, "Efficacy of turmeric extracts and curcumin for alleviating the symptoms of joint arthritis: a systematic review and meta-analysis of randomized clinical trials," Journal of Medicinal Food, vol. 19, no. 8, pp. 717-729, 2016.

[274] G. Derosa, P. Maffioli, L. E. Simental-Mendia, S. Bo, and A. Sahebkar, "Effect of curcumin on circulating interleukin-6 concentrations: a systematic review and meta-analysis of randomized controlled trials," Pharmacological Research, vol. 111, pp. 394-404, 2016.

[275] A. Sahebkar, A. F. Cicero, L. E. Simental-Mendia, B. B. Aggarwal, and S. C. Gupta, "Curcumin downregulates human tumor necrosis factor-alpha levels: a systematic review and meta-analysis of randomized controlled trials," Pharmacological Research, vol. 107, pp. 234-242, 2016.

[276] R. Dantzer, J. C. O'Connor, G. G. Freund, R. W. Johnson, and K. W. Kelley, "From inflammation to sickness and depression: when the immune system subjugates the brain," Nature Reviews. Neuroscience, vol. 9, no. 1, pp. 46-56, 2008.

[277] L. McNally, Z. Bhagwagar, and J. Hannestad, "Inflammation, glutamate, and glia in depression: a literature review," CNS Spectrums, vol. 13, no. 6, pp. 501-510, 2008.

[278] A. H. Miller, V. Maletic, and C. L. Raison, "Inflammation and its discontents: the role of cytokines in the pathophysiology of major depression," Biological Psychiatry, vol. 65, no. 9, pp. 732-741, 2009.

[279] R. A. Khairova, R. Machado-Vieira, J. Du, and H. K. Manji, "A potential role for pro-inflammatory cytokines in regulating synaptic plasticity in major depressive disorder," The International Journal of Neuropsychopharmacology, vol. 12, no. 4, pp. 561-578, 2009.

[280] L. L. Altshuler, O. A. Abulseoud, L. Foland-Ross et al., "Amygdala astrocyte reduction in subjects with major depressive disorder but not bipolar disorder," Bipolar Disorders, vol. 12, no. 5, pp. 541-549, 2010.

[281] M. J. Webster, M. B. Knable, N. Johnston-Wilson, K. Nagata, M. Inagaki, and R. H. Yolken, "Immunohistochemical localization of phosphorylated glial fibrillary acidic protein in the prefrontal cortex and hippocampus from patients with schizophrenia, bipolar disorder, and depression," Brain, Behavior, and Immunity, vol. 15, no. 4, pp. 388-400, 2001.

[282] X. Si, J. J. Miguel-Hidalgo, G. O'Dwyer, C. A. Stockmeier, and G. Rajkowska, "Age-dependent reductions in the level of glial fibrillary acidic protein in the prefrontal cortex in major depression," Neuropsychopharmacology, vol. 29, no. 11, pp. 2088-2096, 2004.

[283] F. Nanjo, K. Goto, R. Seto, M. Suzuki, M. Sakai, and Y. Hara, "Scavenging effects of tea catechins and their derivatives on 1,1-diphenyl-2-picrylhydrazyl radical," Free Radical Biology \& Medicine, vol. 21, no. 6, pp. 895-902, 1996.

[284] N. Salah, N. J. Miller, G. Paganga, L. Tijburg, G. P. Bolwell, and C. Rice-Evans, "Polyphenolic flavanols as scavengers of aqueous phase radicals and as chain-breaking antioxidants," Archives of Biochemistry and Biophysics, vol. 322, no. 2, pp. 339-346, 1995.

[285] M. H. Pan, S. Y. Lin-Shiau, C. T. Ho, J. H. Lin, and J. K. Lin, "Suppression of lipopolysaccharide-induced nuclear factorkappaB activity by theaflavin-3,3'-digallate from black tea and other polyphenols through down-regulation of IkappaB kinase activity in macrophages," Biochemical Pharmacology, vol. 59, no. 4, pp. 357-367, 2000.

[286] T. M. Haqqi, D. D. Anthony, S. Gupta et al., "Prevention of collagen-induced arthritis in mice by a polyphenolic fraction from green tea," Proceedings of the National Academy of Sciences of the United States of America, vol. 96, no. 8, pp. 4524-4529, 1999.

[287] A. Jelenkovic, M. D. Jovanovic, I. Stevanovic et al., "Influence of the green tea leaf extract on neurotoxicity of aluminium chloride in rats," Phytotherapy Research, vol. 28, no. 1, pp. 82-87, 2014.

[288] S. Mandel, T. Amit, O. Bar-Am, and M. B. Youdim, "Iron dysregulation in Alzheimer's disease: multimodal brain permeable iron chelating drugs, possessing neuroprotectiveneurorescue and amyloid precursor protein-processing regulatory activities as therapeutic agents," Progress in Neurobiology, vol. 82, no. 6, pp. 348-360, 2007.

[289] Y. Levites, T. Amit, S. Mandel, and M. B. Youdim, "Neuroprotection and neurorescue against Abeta toxicity and PKCdependent release of nonamyloidogenic soluble precursor 
protein by green tea polyphenol (-)-epigallocatechin-3-gallate," The FASEB Journal, vol. 17, no. 8, pp. 952-954, 2003.

[290] K. Ono, Y. Yoshiike, A. Takashima, K. Hasegawa, H. Naiki, and M. Yamada, "Potent anti-amyloidogenic and fibrildestabilizing effects of polyphenols in vitro: implications for the prevention and therapeutics of Alzheimer's disease," Journal of Neurochemistry, vol. 87, no. 1, pp. 172-181, 2003.

[291] Y. Levites, T. Amit, M. B. Youdim, and S. Mandel, "Involvement of protein kinase $\mathrm{C}$ activation and cell survival/cell cycle genes in green tea polyphenol (-)-epigallocatechin 3-gallate neuroprotective action," The Journal of Biological Chemistry, vol. 277, no. 34, pp. 30574-30580, 2002.

[292] C. W. Chou, W. J. Huang, L. T. Tien, and S. J. Wang, "(-)-Epigallocatechin gallate, the most active polyphenolic catechin in green tea, presynaptically facilitates $\mathrm{Ca} 2+$-dependent glutamate release via activation of protein kinase $\mathrm{C}$ in rat cerebral cortex," Synapse, vol. 61, no. 11, pp. 889-902, 2007.

[293] T. V. Bliss and G. L. Collingridge, "A synaptic model of memory: long-term potentiation in the hippocampus," Nature, vol. 361, no. 6407, pp. 31-39, 1993.

[294] J. T. Wroblewski and W. Danysz, "Modulation of glutamate receptors: molecular mechanisms and functional implications," Annual Review of Pharmacology and Toxicology, vol. 29, pp. 441-474, 1989.

[295] W. Xie, N. Ramakrishna, A. Wieraszko, and Y. W. Hwang, "Promotion of neuronal plasticity by (-)-epigallocatechin-3gallate," Neurochemical Research, vol. 33, no. 5, pp. 776$783,2008$.

[296] J. Ding, G. Fu, Y. Zhao et al., "EGCG ameliorates the suppression of long-term potentiation induced by ischemia at the Schaffer collateral-CA1 synapse in the rat," Cellular and Molecular Neurobiology, vol. 32, no. 2, pp. 267-277, 2012.

[297] A. M. Haque, M. Hashimoto, M. Katakura, Y. Tanabe, Y. Hara, and O. Shido, "Long-term administration of green tea catechins improves spatial cognition learning ability in rats," The Journal of Nutrition, vol. 136, no. 4, pp. 10431047, 2006.

[298] U. Gundimeda, T. H. McNeill, T. K. Fan et al., "Green tea catechins potentiate the neuritogenic action of brainderived neurotrophic factor: role of $67-\mathrm{kDa}$ laminin receptor and hydrogen peroxide," Biochemical and Biophysical Research Communications, vol. 445, no. 1, pp. 218-224, 2014.

[299] E. Kesse-Guyot, L. Fezeu, V. A. Andreeva et al., "Total and specific polyphenol intakes in midlife are associated with cognitive function measured 13 years later," The Journal of Nutrition, vol. 142, no. 1, pp. 76-83, 2012.

[300] T. P. Ng, L. Feng, M. Niti, E. H. Kua, and K. B. Yap, “Tea consumption and cognitive impairment and decline in older Chinese adults," The American Journal of Clinical Nutrition, vol. 88, no. 1, pp. 224-231, 2008.

[301] S. Kuriyama, A. Hozawa, K. Ohmori et al., "Green tea consumption and cognitive function: a cross-sectional study from the Tsurugaya project 1," The American Journal of Clinical Nutrition, vol. 83, no. 2, pp. 355-361, 2006.

[302] S. Borgwardt, F. Hammann, K. Scheffler, M. Kreuter, J. Drewe, and C. Beglinger, "Neural effects of green tea extract on dorsolateral prefrontal cortex," European Journal of Clinical Nutrition, vol. 66, no. 11, pp. 1187-1192, 2012.

[303] E. J. Okello, A. M. Abadi, and S. A. Abadi, "Effects of green and black tea consumption on brain wave activities in healthy volunteers as measured by a simplified electroencephalogram
(EEG): a feasibility study," Nutritional Neuroscience, vol. 19, no. 5, pp. 196-205, 2016.

[304] D. G. Soares, A. C. Andreazza, and M. Salvador, "Sequestering ability of butylated hydroxytoluene, propyl gallate, resveratrol, and vitamins $\mathrm{C}$ and $\mathrm{E}$ against $\mathrm{ABTS}, \mathrm{DPPH}$, and hydroxyl free radicals in chemical and biological systems," Journal of Agricultural and Food Chemistry, vol. 51, no. 4, pp. 1077-1080, 2003.

[305] J. Wang, L. Ho, W. Zhao et al., "Grape-derived polyphenolics prevent Abeta oligomerization and attenuate cognitive deterioration in a mouse model of Alzheimer's disease," The Journal of Neuroscience, vol. 28, no. 25, pp. 6388-6392, 2008.

[306] T. C. Huang, K. T. Lu, Y. Y. Wo, Y. J. Wu, and Y. L. Yang, "Resveratrol protects rats from Abeta-induced neurotoxicity by the reduction of iNOS expression and lipid peroxidation," PloS One, vol. 6, no. 12, article e29102, 2011.

[307] B. Dasgupta and J. Milbrandt, "Resveratrol stimulates AMP kinase activity in neurons," Proceedings of the National Academy of Sciences of the United States of America, vol. 104, no. 17, pp. 7217-7222, 2007.

[308] D. Liu, Q. Zhang, J. Gu et al., "Resveratrol prevents impaired cognition induced by chronic unpredictable mild stress in rats," Progress in Neuro-Psychopharmacology \& Biological Psychiatry, vol. 49, pp. 21-29, 2014.

[309] Z. Wang, J. Gu, X. Wang et al., "Antidepressant-like activity of resveratrol treatment in the forced swim test and tail suspension test in mice: the HPA axis. BDNF expression and phosphorylation of ERK," Pharmacology, Biochemistry, and Behavior, vol. 112, pp. 104-110, 2013.

[310] J. H. Jang and Y. J. Surh, "Protective effect of resveratrol on beta-amyloid-induced oxidative PC12 cell death," Free Radical Biology \& Medicine, vol. 34, no. 8, pp. 1100-1110, 2003.

[311] D. Kim, M. D. Nguyen, M. M. Dobbin et al., "SIRT1 deacetylase protects against neurodegeneration in models for Alzheimer's disease and amyotrophic lateral sclerosis," The EMBO Journal, vol. 26, no. 13, pp. 3169-3179, 2007.

[312] B. L. Tang, "Resveratrol is neuroprotective because it is not a direct activator of Sirt1-A hypothesis," Brain Research Bulletin, vol. 81, no. 4-5, pp. 359-361, 2010.

[313] D. R. Valenzano, E. Terzibasi, T. Genade, A. Cattaneo, L. Domenici, and A. Cellerino, "Resveratrol prolongs lifespan and retards the onset of age-related markers in a short-lived vertebrate," Current Biology, vol. 16, no. 3, pp. 296-300, 2006.

[314] X. Yu and G. Li, "Effects of resveratrol on longevity, cognitive ability and aging-related histological markers in the annual fish Nothobranchius guentheri," Experimental Gerontology, vol. 47, no. 12, pp. 940-949, 2012.

[315] K. T. Howitz, K. J. Bitterman, H. Y. Cohen et al., "Small molecule activators of sirtuins extend Saccharomyces cerevisiae lifespan," Nature, vol. 425, no. 6954, pp. 191-196, 2003.

[316] G. Torres, J. N. Dileo, B. H. Hallas, J. M. Horowitz, and J. R. Leheste, "Silent information regulator 1 mediates hippocampal plasticity through presenilin1," Neuroscience, vol. 179, pp. 32-40, 2011.

[317] X. Wang, Y. Xie, T. Zhang et al., "Resveratrol reverses chronic restraint stress-induced depression-like behaviour: involvement of BDNF level, ERK phosphorylation and expression of Bcl-2 and Bax in rats," Brain Research Bulletin, vol. 125, pp. 134-143, 2016.

[318] L. L. Hurley, L. Akinfiresoye, O. Kalejaiye, and Y. Tizabi, "Antidepressant effects of resveratrol in an animal model 
of depression," Behavioural Brain Research, vol. 268, pp. 1-7, 2014.

[319] Y. Yazir, T. Utkan, N. Gacar, and F. Aricioglu, "Resveratrol exerts anti-inflammatory and neuroprotective effects to prevent memory deficits in rats exposed to chronic unpredictable mild stress," Physiology \& Behavior, vol. 138, pp. 297-304, 2015.

[320] D. Liu, K. Xie, X. Yang et al., "Resveratrol reverses the effects of chronic unpredictable mild stress on behavior, serum corticosterone levels and BDNF expression in rats," Behavioural Brain Research, vol. 264, pp. 9-16, 2014.

[321] R. Krikorian, T. A. Nash, M. D. Shidler, B. Shukitt-Hale, and J. A. Joseph, "Concord grape juice supplementation improves memory function in older adults with mild cognitive impairment," The British Journal of Nutrition, vol. 103, no. 5, pp. 730-734, 2010.

[322] A. V. Witte, L. Kerti, D. S. Margulies, and A. Floel, "Effects of resveratrol on memory performance, hippocampal functional connectivity, and glucose metabolism in healthy older adults," The Journal of Neuroscience, vol. 34, no. 23, pp. 7862-7870, 2014.

[323] T. Walle, "Bioavailability of resveratrol," Annals of the new York Academy of Sciences, vol. 1215, pp. 9-15, 2011.

[324] G. Singh and R. S. Pai, "Optimized PLGA nanoparticle platform for orally dosed trans-resveratrol with enhanced bioavailability potential," Expert Opinion on Drug Delivery, vol. 11, no. 5, pp. 647-659, 2014.

[325] O. L. Blanchard, G. Friesenhahn, M. A. Javors, and J. M. Smoliga, "Development of a lozenge for oral transmucosal delivery of trans-resveratrol in humans: proof of concept," PloS One, vol. 9, no. 2, article e90131, 2014.

[326] L. Marzocchella, M. Fantini, M. Benvenuto et al., "Dietary flavonoids: molecular mechanisms of action as antiinflammatory agents," Recent Patents on Inflammation \& Allergy Drug Discovery, vol. 5, no. 3, pp. 200-220, 2011.

[327] T. M. du Bois, C. Deng, W. Bell, and X. F. Huang, "Fatty acids differentially affect serotonin receptor and transporter binding in the rat brain," Neuroscience, vol. 139, no. 4, pp. 1397-1403, 2006.

[328] C. R. Jones, T. Arai, and S. I. Rapoport, "Evidence for the involvement of docosahexaenoic acid in cholinergic stimulated signal transduction at the synapse," Neurochemical Research, vol. 22, no. 6, pp. 663-670, 1997.

[329] P. Flachs, O. Horakova, P. Brauner et al., "Polyunsaturated fatty acids of marine origin upregulate mitochondrial biogenesis and induce beta-oxidation in white fat," Diabetologia, vol. 48, no. 11, pp. 2365-2375, 2005.

[330] F. Pifferi, F. Roux, B. Langelier et al., "(n-3) polyunsaturated fatty acid deficiency reduces the expression of both isoforms of the brain glucose transporter GLUT1 in rats," The Journal of Nutrition, vol. 135, no. 9, pp. 2241-2246, 2005.

[331] A. Wu, Z. Ying, and F. Gomez-Pinilla, "Dietary omega-3 fatty acids normalize BDNF levels, reduce oxidative damage, and counteract learning disability after traumatic brain injury in rats," Journal of Neurotrauma, vol. 21, no. 10, pp. 14571467,2004

[332] E. Tyagi, Y. Zhuang, R. Agrawal, Z. Ying, and F. GomezPinilla, "Interactive actions of Bdnf methylation and cell metabolism for building neural resilience under the influence of diet," Neurobiology of Disease, vol. 73, pp. 307$318,2015$.
[333] H. Suzuki, Y. Morikawa, and H. Takahashi, "Effect of DHA oil supplementation on intelligence and visual acuity in the elderly," World Review of Nutrition and Dietetics, vol. 88, pp. 68-71, 2001.

[334] P. Weill, B. Schmitt, G. Chesneau, N. Daniel, F. Safraou, and P. Legrand, "Effects of introducing linseed in livestock diet on blood fatty acid composition of consumers of animal products," Annals of Nutrition \& Metabolism, vol. 46, no. 5, pp. 182-191, 2002.

[335] P. Astorg, N. Arnault, S. Czernichow, N. Noisette, P. Galan, and S. Hercberg, "Dietary intakes and food sources of n-6 and n-3 PUFA in French adult men and women," Lipids, vol. 39, no. 6, pp. 527-535, 2004.

[336] A. J. Sinclair, D. Begg, M. Mathai, and R. S. Weisinger, "Omega 3 fatty acids and the brain: review of studies in depression," Asia Pacific Journal of Clinical Nutrition, vol. 16, Supplement 1, pp. 391-397, 2007.

[337] B. M. McGahon, D. S. Martin, D. F. Horrobin, and M. A. Lynch, "Age-related changes in synaptic function: analysis of the effect of dietary supplementation with omega- 3 fatty acids," Neuroscience, vol. 94, no. 1, pp. 305-314, 1999.

[338] A. Wu, Z. Ying, and F. Gomez-Pinilla, "Omega-3 fatty acids supplementation restores mechanisms that maintain brain homeostasis in traumatic brain injury," Journal of Neurotrauma, vol. 24, no. 10, pp. 1587-1595, 2007.

[339] S. Kalmijn, L. J. Launer, A. Ott, J. C. Witteman, A. Hofman, and M. M. Breteler, "Dietary fat intake and the risk of incident dementia in the Rotterdam study," Annals of Neurology, vol. 42, no. 5, pp. 776-782, 1997.

[340] P. Barberger-Gateau, L. Letenneur, V. Deschamps, K. Peres, J. F. Dartigues, and S. Renaud, "Fish, meat, and risk of dementia: cohort study," $B M J$, vol. 325 , no. 7370, pp. 932-933, 2002.

[341] M. C. Morris, D. A. Evans, J. L. Bienias et al., "Dietary fats and the risk of incident Alzheimer disease," Archives of Neurology, vol. 60, no. 2, pp. 194-200, 2003.

[342] S. M. Conklin, P. J. Gianaros, S. M. Brown et al., "Long-chain omega-3 fatty acid intake is associated positively with corticolimbic gray matter volume in healthy adults," Neuroscience Letters, vol. 421, no. 3, pp. 209-212, 2007.

[343] C. A. Raji, K. I. Erickson, O. L. Lopez et al., "Regular fish consumption and age-related brain gray matter loss," American Journal of Preventive Medicine, vol. 47, no. 4, pp. 444-451, 2014.

[344] E. L. Boespflug, R. K. McNamara, J. C. Eliassen, M. D. Schidler, and R. Krikorian, "Fish oil supplementation increases event-related posterior cingulate activation in older adults with subjective memory impairment," The Journal of Nutrition, Health \& Aging, vol. 20, no. 2, pp. 161-169, 2016.

[345] E. J. Schaefer, V. Bongard, A. S. Beiser et al., "Plasma phosphatidylcholine docosahexaenoic acid content and risk of dementia and Alzheimer disease: the Framingham heart study," Archives of Neurology, vol. 63, no. 11, pp. 15451550, 2006.

[346] S. Kotani, E. Sakaguchi, S. Warashina et al., "Dietary supplementation of arachidonic and docosahexaenoic acids improves cognitive dysfunction," Neuroscience Research, vol. 56, no. 2, pp. 159-164, 2006.

[347] M. K. Zamroziewicz, E. J. Paul, R. D. Rubin, and A. K. Barbey, "Anterior cingulate cortex mediates the relationship between 
O3PUFAs and executive functions in APOE e4 carriers," Frontiers in Aging Neuroscience, vol. 7, p. 87, 2015.

[348] P. A. Dacks, D. W. Shineman, and H. M. Fillit, "Current evidence for the clinical use of long-chain polyunsaturated n-3 fatty acids to prevent age-related cognitive decline and Alzheimer's disease," The Journal of Nutrition, Health \& Aging, vol. 17, no. 3, pp. 240-251, 2013.

[349] S. Fusco and G. Pani, "Brain response to calorie restriction," Cellular and Molecular Life Sciences, vol. 70, no. 17, pp. 3157-3170, 2013.

[350] A. Strom and R. A. Jensen, "Mortality from circulatory diseases in Norway 1940-1945," Lancet, vol. 1, no. 6647, pp. 126-129, 1951.

[351] J. Most, V. Tosti, L. M. Redman, and L. Fontana, "Calorie restriction in humans: an update," Ageing Research Reviews, 2016.

[352] A. V. Witte, M. Fobker, R. Gellner, S. Knecht, and A. Floel, "Caloric restriction improves memory in elderly humans," Proceedings of the National Academy of Sciences of the United States of America, vol. 106, no. 4, pp. 12551260, 2009.

[353] N. Weraarchakul, R. Strong, W. G. Wood, and A. Richardson, "The effect of aging and dietary restriction on DNA repair," Experimental Cell Research, vol. 181, no. 1, pp. 197-204, 1989.

[354] G. Pani, "P66SHC and ageing: ROS and TOR?" Aging (Albany NY), vol. 2, no. 8, pp. 514-518, 2010.

[355] L. Fontana, S. Klein, and J. O. Holloszy, "Effects of long-term calorie restriction and endurance exercise on glucose tolerance, insulin action, and adipokine production," Age (Dordrecht, Netherlands), vol. 32, no. 1, pp. 97-108, 2010.

[356] M. Pae, S. N. Meydani, and D. Wu, "The role of nutrition in enhancing immunity in aging," Aging and Disease, vol. 3, no. 1, pp. 91-129, 2012.

[357] F. Sabatino, E. J. Masoro, C. A. McMahan, and R. W. Kuhn, "Assessment of the role of the glucocorticoid system in aging processes and in the action of food restriction," Journal of Gerontology, vol. 46, no. 5, pp. B171-B179, 1991.

[358] L. M. Redman and E. Ravussin, "Endocrine alterations in response to calorie restriction in humans," Molecular and Cellular Endocrinology, vol. 299, no. 1, pp. 129-136, 2009.

[359] M. P. Mattson, W. Duan, and Z. Guo, "Meal size and frequency affect neuronal plasticity and vulnerability to disease: cellular and molecular mechanisms," Journal of Neurochemistry, vol. 84, no. 3, pp. 417-431, 2003.

[360] A. Fontan-Lozano, J. L. Saez-Cassanelli, M. C. Inda et al., "Caloric restriction increases learning consolidation and facilitates synaptic plasticity through mechanisms dependent on NR2B subunits of the NMDA receptor," The Journal of Neuroscience, vol. 27, no. 38, pp. 10185-10195, 2007.

[361] B. G. Mockett and S. R. Hulme, "Metaplasticity: new insights through electrophysiological investigations," Journal of Integrative Neuroscience, vol. 7, no. 2, pp. 315-336, 2008.

[362] M. M. Adams, L. Shi, M. C. Linville et al., "Caloric restriction and age affect synaptic proteins in hippocampal CA3 and spatial learning ability," Experimental Neurology, vol. 211, no. 1, pp. 141-149, 2008.

[363] S. M. Rothman and M. P. Mattson, "Activity-dependent, stress-responsive BDNF signaling and the quest for optimal brain health and resilience throughout the lifespan," Neuroscience, vol. 239, pp. 228-240, 2013.
[364] W. T. Cefalu, A. D. Bell-Farrow, Z. Q. Wang et al., "Caloric restriction decreases age-dependent accumulation of the glycoxidation products, $\mathrm{N}$ epsilon-(carboxymethyl)lysine and pentosidine, in rat skin collagen," The Journals of Gerontology. Series a, Biological Sciences and Medical Sciences, vol. 50, no. 6, pp. B337-B341, 1995.

[365] Z. F. Yu and M. P. Mattson, "Dietary restriction and 2deoxyglucose administration reduce focal ischemic brain damage and improve behavioral outcome: evidence for a preconditioning mechanism," Journal of Neuroscience Research, vol. 57, no. 6, pp. 830-839, 1999.

[366] R. M. Anson, Z. Guo, R. de Cabo et al., "Intermittent fasting dissociates beneficial effects of dietary restriction on glucose metabolism and neuronal resistance to injury from calorie intake," Proceedings of the National Academy of Sciences of the United States of America, vol. 100, no. 10, pp. 62166220, 2003.

[367] P. D. Loprinzi, A. Branscum, J. Hanks, and E. Smit, "Healthy lifestyle characteristics and their joint association with cardiovascular disease biomarkers in US adults," Mayo Clinic Proceedings, vol. 91, no. 4, pp. 432-442, 2016.

[368] C. S. Green and D. Bavelier, "Exercising your brain: a review of human brain plasticity and training-induced learning," Psychology and Aging, vol. 23, no. 4, pp. 692-701, 2008.

[369] Association As, Think about Your Future. Maintain Your Brain Today.

[370] AARP, Staying sharp, AARP, December 2016, https:// stayingsharp.aarp.org/what-is-staying-sharp.

[371] A. Solomon, E. Levälahti, H. Soininen et al., "A multidomain, two-year, randomized controlled trial to prevent cognitive impairment: the finger study," Alzheimer's \& Dementia, vol. 10, no. 4, pp. 137-138, 2014. 

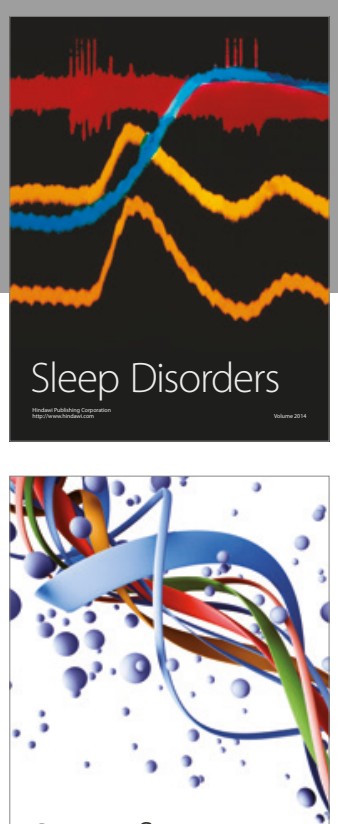

Scientifica
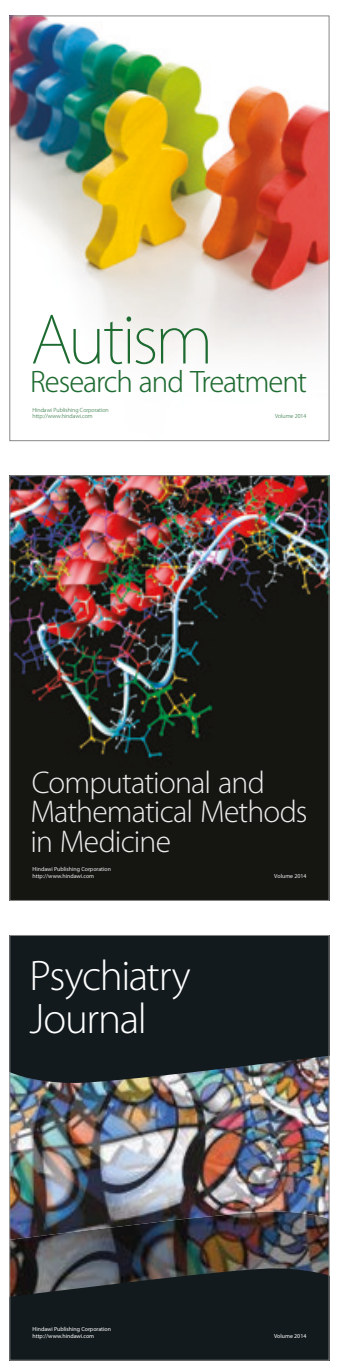
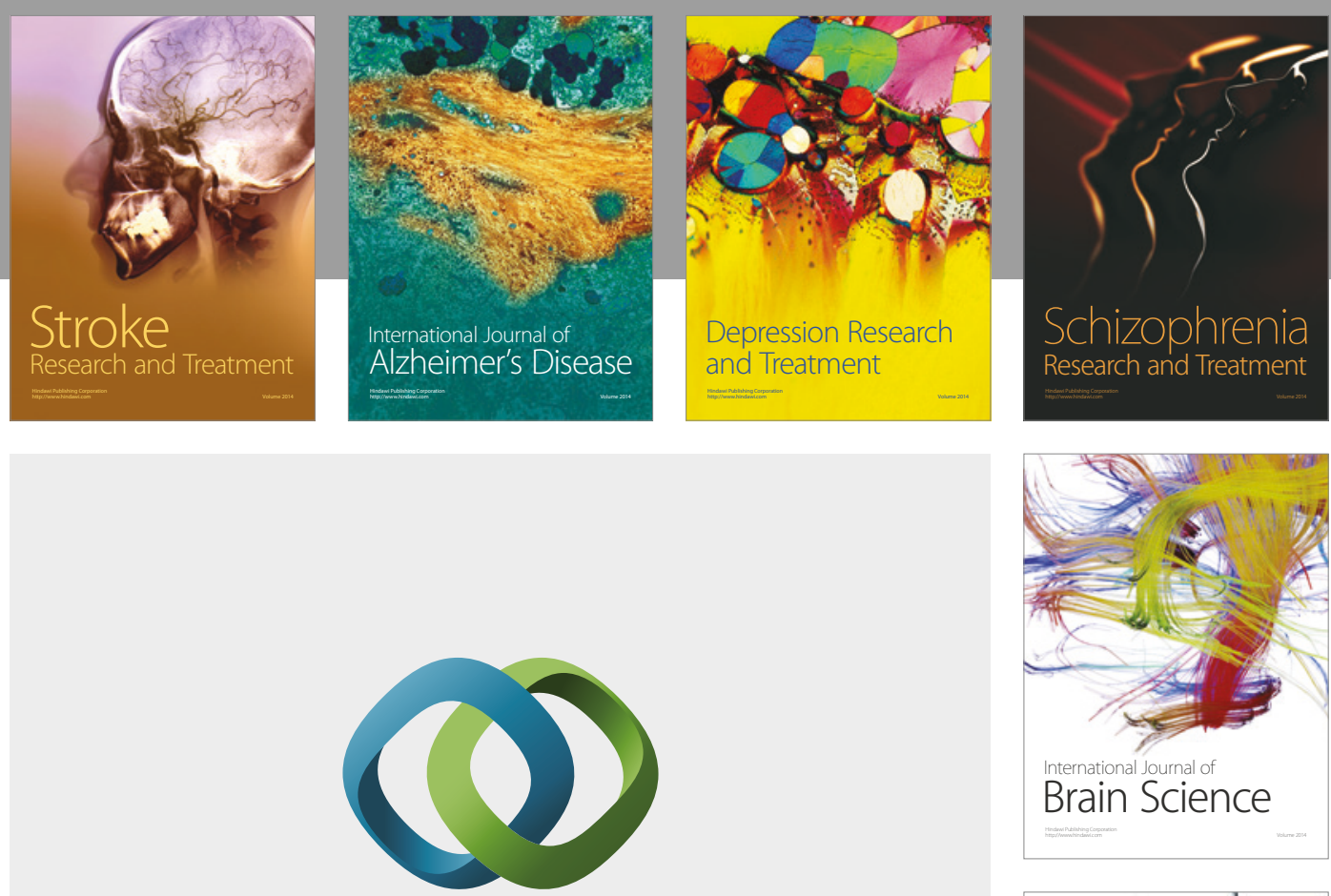

\section{Hindawi}

Submit your manuscripts at

https://www.hindawi.com
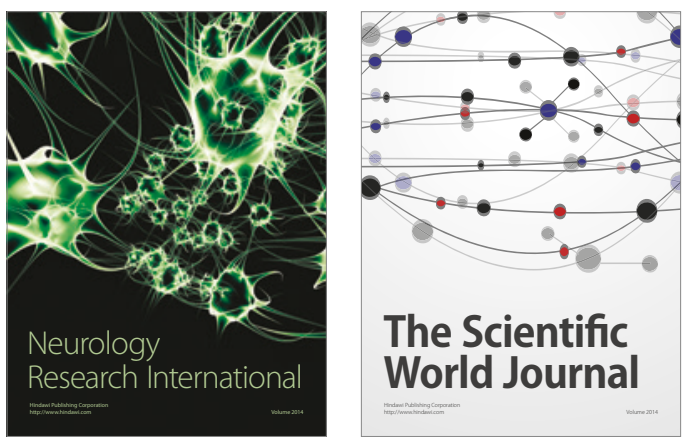

The Scientific World Journal

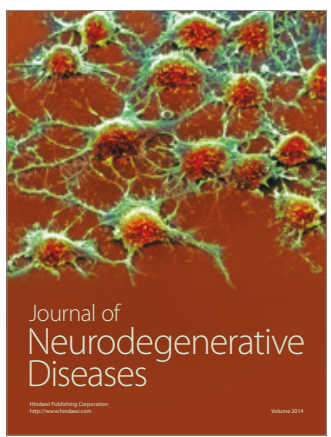

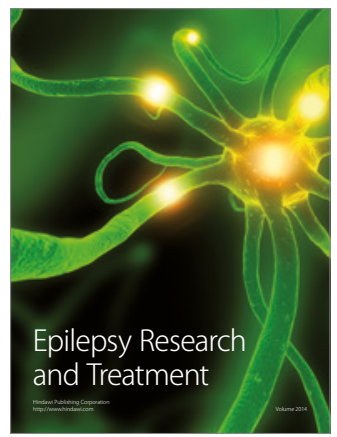

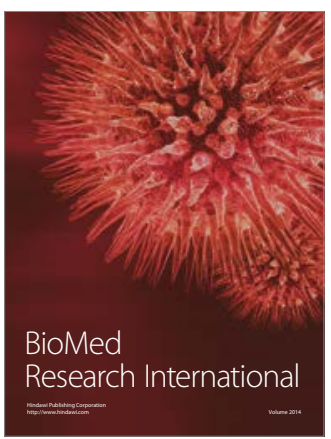

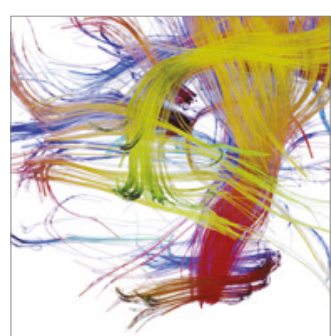

Brain Science

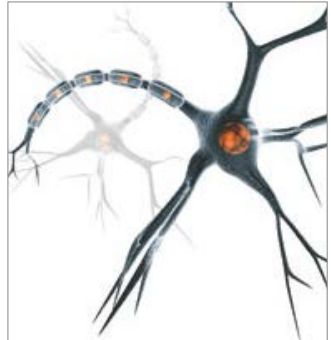

Neural Plasticity
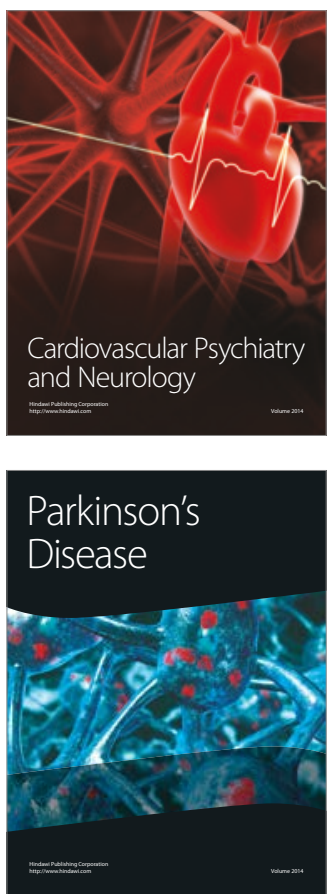